\title{
The Investment Technology of Foreign and Domestic Institutional Investors in an Emerging Market
}

\author{
Ila Patnaik and Ajay Shah
}




\title{
IMF Working Paper
}

Research Department

\section{The Investment Technology of Foreign and Domestic Institutional Investors in an Emerging Market}

\author{
Prepared by Ila Patnaik and Ajay Shah ${ }^{1}$
}

Authorized for distribution by Prakash Loungani

April 2013

\section{This Working Paper should not be reported as representing the views of the IMF.} The views expressed in this Working Paper are those of the author(s) and do not necessarily represent those of the IMF or IMF policy. Working Papers describe research in progress by the author(s) and are published to elicit comments and to further debate.

\begin{abstract}
The literature on the investment technology of foreign versus domestic investors has inconclusive results. This paper revisits the question, with a focus on decomposing portfolio performance into asset allocation and security selection. We document signicant differences in exposure to systematic asset pricing factors between foreign and domestic investors. A quasi-experimental strategy is introduced, for comparing security selection after controlling for diferences in asset allocation. Our results show that foreign investors in India do remarkably poorly at security selection.
\end{abstract}

JEL Classification Numbers: G14, G20

Keywords: Institutional Investor, Foreign Investors, Domestic Institutional Investors Author's E-Mail Address: ipatnaik@imf.org; ajayshah@mayin.org

\footnotetext{
${ }^{1}$ We are grateful to Apoorva Gupta for excellent research assistance. The paper benefited greatly from discussions with Tarun Ramadorai.
} 


\section{Contents}

1 Introduction 3

2 Questions and methodology 5

2.1 Differences in asset allocation . . . . . . . . . . . 6

2.2 Differences in security selection . . . . . . . . . . 7

2.3 The problems of comparing institutional investors against domestic individual investors . . . . . . . . . . . . 8

2.4 Identifying FII vs. DII . . . . . . . . . . . . . . . 8

2.5 Summary of methodology for measuring security selection . . 9

3 Data description $\quad 9$

4 A preliminary exploration $\quad 11$

5 The asset allocation of FIIs and DIIs 14

6 The security selection of FIIs and DIIs 16

6.1 Match balance ................. 20

6.2 Firms that got high FII but low DII investment . . . . . . . 21

6.3 Firms that got high DII but low FII investment . . . . . . . 23

7 Sensitivity analyses $\quad 25$

7.1 Size weights . . . . . . . . . . . . 25

7.2 More extreme definitions for FII and DII dummies . . . . . 26

7.3 Alternative choices of asset pricing factors . . . . . . . . 27

7.3 .1 Liquidity . . . . . . . . . . . . . . 28

7.3 .2 Momentum . . . . . . . . . . . . . 28

8 Conclusions 28

$\begin{array}{ll}\text { Appendix } & 31\end{array}$ 


\section{Introduction}

Policy debates about financial globalisation are closely connected to the investment technology of foreign investors in emerging markets. Do foreign investors bring capital to good projects? Or are foreign investors afflicted with weaknesses of information and analysis, which yields problems such as home bias, misallocation of capital, pro-cyclicality of capital flows, and vulnerability to sudden stops?

The home bias literature has shown that foreign investors often invest in only a small set of firms in an emerging market. As an example, while there are over 5000 listed firms in India, in 2011 there were only 703 firms where foreign investors owned above 5 per cent of the publicly traded (i.e. 'floating') market value. This raises questions about these chosen firms. What is the process of portfolio formation adopted by foreign investors? Do foreign investors possess a strong investment technology, through which their capital is channelled into good projects?

Numerous papers have been written in this literature, with often contradictory results. This paper takes the novel approach of separating the questions of asset allocation and security selection. This is a standard idea in the economics of fund management, going back to the 1960s. Portfolio returns can be decomposed into exposure to systematic asset pricing factors, such as size or book-to-market, as opposed to returns to security selection. Differences in asset allocation reflect the portfolio strategy of the investor, and there can be legitimate reasons for differences in exposures to asset pricing factors. In contrast, performance obtained through security selection unambiguously reflects investment technology.

We analyse the behaviour of foreign versus domestic institutional investors in India and find substantial differences in asset allocation. In some respects, foreign investors take on more risk, and should therefore obtain higher expected returns. In other respects, this operates in reverse; foreign investors take on reduced risk.

We then turn to the question of security selection. After controlling for differences in asset allocation, do foreign investors do well in choosing securities? Specifically, do firms chosen by foreign investors exhibit superior stock market returns? We look beyond the emphasis on returns in the finance perspective to also examine firm fundamentals. Do the firms chosen by foreign investors do better on growth in output, and growth of productivity?

All these outcomes of interest reflect a mix of a selection process (do foreign investors forecast well, and manage to identify firms that are going to do well?) and a treatment effect (does the decision by a foreign investor to buy 
shares in a company help the company do better?). We pursue the reduced form outcome, and make no attempt to disentangle selection from treatment effects.

We devise a quasi-experimental strategy for measuring the ability of foreign or domestic investors to do security selection, after controlling for differences in asset allocation. This involves identifying and addressing numerous threats to validity. Differences between firms in systematic asset pricing factors, such as size, $\mathrm{B} / \mathrm{P}$ and $\beta$, are correlated with future outcomes. As an example, high $\beta$ firms are likely to see high output growth in a business cycle expansion. In order to measure security selection, firms with high foreign institutional investment (but not domestic institutional investment) are matched against firms which got neither. Controls are identified which have similar size, $\mathrm{B} / \mathrm{P}$ and $\beta$ to the chosen firms. The comparison of outcomes identifies the security selection process, without being confounded by differences in asset allocation.

Our results may be summarised as follows. The firms chosen by foreign investors are those that have experienced high growth of capital (when compared with the control) prior to the observation date. They continue to obtain high growth of capital after the observation date. There is some evidence of superior output growth. However, the chosen firms have inferior productivity growth, and deliver inferior stock market returns when compared with the controls.

In contrast, the firms chosen by domestic institutional investors appear to deliver superior returns, and superior productivity growth, in the years after measurement date. This suggests that domestic institutions possess a valuable investment technology.

The methodology and the results of this paper have many implications. The literature on investment technology of foreign versus domestic investors, which has generally emphasised reduced form portfolio returns, has inconclusive results. Our results suggest that differences in the overall portfolio returns reflect a combination of differences in asset allocation and differences in security selection, which may explain how different researchers have obtained different results on the superiority of the investment technology of foreign investors. For foreign investors in India, these results suggest that the returns drag associated with poor capabilities in security selection could be avoided by achieving the desired asset allocation through index funds that express systematic asset pricing factors. The methodology of this paper can be easily extended to other countries, since the data requirements are easily met in all emerging markets.

The remainder of this paper is organised as follows. Section 2 sketches the questions and the measurement strategy. Section 3 describes the dataset 
used in the paper. Section 4 shows reduced form models explaining FII and DII ownership, which helps us obtain greater intuition into the phenomena at work. Section 5 examines the asset allocation choices of foreign and domestic institutional investors and finds substantial differences between the two. Section 6 measures the security selection process, after controlling for differences in asset allocation. Section 7 undertakes a series of modifications to the analysis in order to gauge the sensitivity of the results. Finally, Section 8 concludes.

\section{Questions and methodology}

The presence of home bias is a well established fact in the international finance literature: foreign investors hold relatively low weights in emerging markets. They tend to invest in large and liquid firms with international visibility and better corporate governance.

One strand of this literature has asked the question: Do foreign investors perform well? The presence of home bias, which suggests limitations in the information processing of foreign investors, may imply inferior investment performance by foreign investors. If the investment technology of foreign investors has difficulties, this could encourage investment in index funds that give exposure to emerging markets without engaging in security selection.

These questions are important to the policy debates about financial globalisation. If foreign investors suffer from asymmetric information and thus possess an inferior investment technology, their decisions could induce misallocation. Some of the pathologies identified by the international finance literature, such as the pro-cyclical behaviour of foreign investment or the phenomena of sudden stops and capital flow reversals, could be attributed to poor information processing by foreign investors.

This motivates a careful examination of the investment technology of foreign investors. The existing literature does not have a single unifying model and methodology; a series of papers have obtained diverse datasets, and each has fashioned a methodology suited to the dataset at hand. Dvořák (2005) utilises transaction data from the Jakarta Stock Exchange, and finds that clients of local brokerage firms do well in the short run, but clients of foreign brokerage firms do better in the long run. Choe, Kho, and Stulz (2005) find that foreign investors suffer higher transactions costs in Korea. Froot and Ramadorai (2008) harness a unique identification opportunity by juxtaposing closed-end country fund NAV returns and home country returns. They argue that institutional cross-border flows are based on sound information processing about country fundamentals. Albuquerque, H Bauer, and Schneider (2009) argue that the returns-chasing behaviour of US investors 
can be attributed to superior information, not inferior knowledge or trendfollowing.

The mainstream finance literature on these questions has focused on investment technology in the sense of returns forecasting. We broaden the analysis to also evaluate forecasts of firm fundamentals. A recent paper which has embarked on similar questions with the same dataset is Petkova (2012). As the home bias literature has demonstrated, foreign investors invest in only a small set of firms in an emerging markets. How well does this selectivity process work? Do the firms chosen by foreign investors do well in terms of growth of output and productivity?

While these questions are interesting and important, the analysis faces numerous threats to validity which need to be factored in while constructing a measurement strategy.

\subsection{Differences in asset allocation}

The first challenge is that of distinguishing information processing about securities as opposed to portfolio formation strategies. As an example, the investment mandate or chosen portfolio strategy of a foreign investor may require investment in firms with a market capitalisation of above $\$ 1$ billion. The security selection by this investor must then be judged by comparisons against similar sized firms that were not chosen for investment. Similarly, high beta firms would tend to obtain high growth in a business cycle expansion. This would make it appear that an investor with a high beta asset allocation possesses high quality security selection during a business cycle expansion.

If foreign and domestic institutional investors have divergent portfolio strategies, in the sense of exposures to systematic asset pricing factors, this fact will in itself induce differences in portfolio performance. The investors who accept a greater exposure to risk factors, such as investment in high beta, low size, and high $\mathrm{B} / \mathrm{P}$ firms, will obtain superior returns. This difference in returns should be interpreted as returns to asset allocation, and not related to information processing or forecasting about emerging market firms. Indeed, given that asset allocation is often largely determined by the investment mandate, to a substantial extent, differences in asset allocation between foreign and domestic investors should not be attributed to differences in the investment technology of foreign or domestic investors.

Our first objective is thus to measure the asset allocation of domestic versus foreign investors. The empirical asset pricing literature suggests that the Fama-French factors - size, $\mathrm{B} / \mathrm{P}$, and $\beta$ - explain the bulk of the variation 
in portfolio performance. In our sensitivity analyses, we will also explore liquidity and momentum as potentially important asset pricing factors.

\subsection{Differences in security selection}

The evidence offered ahead shows that foreign and domestic investors differ strongly in their choices on size, $\mathrm{B} / \mathrm{P}$ and $\beta$. Traditional regression analysis would attempt to control for these differences by running regressions where size, $\mathrm{B} / \mathrm{P}$ and $\beta$ are present as controls. However, such analysis suffers from two key problems: (a) The true relationships may be nonlinear and (b) When there is a lack of match balance, conventional regression involves extrapolation, which is fraught with estimation risk.

Hence, we embark on a matching process, where each firm that was chosen by FIIs (or DIIs) is matched against a partner that got neither FII nor DII investment, where the chosen firm and the partner have similar values for size, $\mathrm{B} / \mathrm{P}$ and $\beta$. If a high quality match is not obtained, the firm is deleted from the dataset. This ensures a high quality design which gives us the ability to focus on security selection without being confounded by differences in asset allocation.

The questions of interest involve a complex interplay between selectivity effects and treatment effects. Foreign investment is not a treatment in the sense of the literature on treatment effects. When a foreign investor buys shares on the secondary market, in some respects, the firm is unaffected. Further, foreign investors can flit in and out of ownership of the company. From this viewpoint, the phenomenon of interest is selection: Do foreign investors do well in forecasting future stock market returns and thus pick winner? Do the firms that they choose experience high growth in output and productivity?

If the question under analysis were purely about treatment effects, then propensity score matching would have been appropriate. However, to the extent that the mechanism of selection is the phenomenon of interest, propensity score matching is inappropriate. ${ }^{1}$

At the same time, there may also be an element of a casual impact of foreign investment upon the firm. Foreign investors might get involved in corporate governance and thus improve the functioning of the firm. In a model of

\footnotetext{
${ }^{1}$ As an example, consider a firm characteristic $X$ (e.g. export intensity) that is used by FIIs in identifying firms to invest in. If $X$ is present in the logit model used for propensity score matching, then the matched control will have similar values for $X$. However, this may obscure the phenomenon of interest. If FIIs select firms for investment using export intensity, and if this yields high quality investments, this phenomenon would not be captured by propensity score matching.
} 
imperfect capital market integration such as Merton (1987), the entry of foreign investors into a firm may be associated with enhanced stock prices, and may enable improved access to equity and debt financing which may fuel growth of capital. If firms are financially constrained, this might make it possible for them to take up good quality projects and thus obtain sharp improvements in output and productivity.

In this paper, we recognise that both selection and treatment effects are present, and make no attempt to disentangle them. We focus on the reduced form question: Regardless of whether this is owing to selection or treatment effects, do the firms chosen for investment by foreign investment fare well in the future, in terms of growth in output, productivity and stock market returns?

\subsection{The problems of comparing institutional investors against domestic individual investors}

Most foreign investment in emerging markets is done by institutional investors, while most investors in emerging markets are individuals. An extensive literature in financial intermediation has emphasised the unique decision problems of institutional investors. A more recent household finance literature has identified unique features of the behaviour of individual investors.

In order to avoid comparisions between foreign institutional investors against domestic individual investors, we compare the behaviour of foreign institutional investors (FII) against domestic institutional investors (DII).

\subsection{Identifying FII vs. DII}

The simplest estimation strategy would involve running regressions explaining an outcome (e.g. output growth) from time $t$ to time $t+k$ on ownership structure at time $t$. This would suffer from the problem that many firms have both domestic and foreign institutional investment. The phenomena of interest are not identified for these firms.

Hence, we devise a quasi-experimental strategy by identifying two groups of firms: Those with high FII investment but not DII investment, and vice versa. The former set is the firms chosen by FIIs for investment but shunned by DIIs, and the latter is the firms chosen by DIIs for investment by shunned by FIIs. The comparison of performance by these firms would highlight the differences in information processing (and potential treatment effects) by FIIs vs. DIIs. 
Table 1 Industry Composition

This table shows the number of firms in each major industry group, in each year, of the dataset under examination. In addition to manufacturing firms, we also observe many services firms. As an example, there were 155 information technology firms in 2001, which went up to 206 in 2011.

\begin{tabular}{llllllllllll}
\hline & 2001 & 2002 & 2003 & 2004 & 2005 & 2006 & 2007 & 2008 & 2009 & 2010 & 2011 \\
\hline Chemicals & 482 & 509 & 551 & 516 & 522 & 506 & 578 & 574 & 578 & 570 & 571 \\
Diversified & 33 & 34 & 34 & 31 & 34 & 38 & 40 & 42 & 42 & 42 & 42 \\
Electricity & 11 & 12 & 12 & 13 & 15 & 17 & 17 & 21 & 22 & 23 & 24 \\
Food & 193 & 211 & 223 & 210 & 210 & 208 & 247 & 252 & 251 & 246 & 252 \\
Machinery & 254 & 273 & 264 & 268 & 267 & 265 & 287 & 288 & 284 & 279 & 283 \\
Metals & 179 & 199 & 203 & 202 & 204 & 204 & 244 & 249 & 249 & 241 & 243 \\
Mining & 18 & 21 & 22 & 20 & 22 & 23 & 26 & 26 & 28 & 29 & 32 \\
MiscManuf & 101 & 108 & 106 & 104 & 102 & 111 & 136 & 137 & 138 & 141 & 139 \\
NonMetalMin & 114 & 127 & 132 & 125 & 124 & 121 & 135 & 135 & 138 & 137 & 142 \\
Serv.Construction & 109 & 116 & 112 & 110 & 116 & 124 & 141 & 160 & 166 & 175 & 191 \\
Serv.IT & 155 & 151 & 167 & 153 & 154 & 154 & 182 & 195 & 195 & 200 & 206 \\
Serv.Other & 460 & 480 & 479 & 444 & 455 & 475 & 544 & 543 & 529 & 537 & 578 \\
Textiles & 248 & 274 & 285 & 272 & 266 & 264 & 307 & 305 & 298 & 292 & 299 \\
TransportEq & 90 & 95 & 92 & 90 & 98 & 100 & 113 & 113 & 117 & 117 & 115 \\
Sum & 2447 & 2610 & 2682 & 2558 & 2589 & 2610 & 2997 & 3040 & 3035 & 3029 & 3117 \\
\hline \hline
\end{tabular}

\subsection{Summary of methodology for measuring security selec- tion}

In summary, our strategy for measuring capabilities in security selection, after controlling for differences in asset allocation, works in three steps:

1. At each year, identify a 'High FII' set of firms, with high FII investment but low DII investment, and a 'High DII' set of firms, with high DII investment but low FII investment. A third set of firms of interest is 'None', where there is neither FII nor DII investment.

2. For each firm in these two sets, identify a partner from the set 'None' that has similar size, $\mathrm{B} / \mathrm{P}$ and $\beta$. Reject chosen firms where a high quality match cannot be obtained.

3. This leaves us holding a dataset containing $N$ firms with high FII investment (but not DII investment) and another $N$ firms with neither FII investment nor DII investment, where the two sets are matched by size, $\mathrm{B} / \mathrm{P}$ and $\beta$. Observations across many years are pooled into this dataset. This permits regressions of the form $y_{i, t+k}-y_{i, t}=a_{0}+a_{1} D+e_{i, t}$ where the growth in $y$ is explained using the dummy variable $D$ which denotes high FII investment. Clustered and heteroscedasticity-robust standard errors are reported.

\section{Data description}

The dataset for our analysis is drawn from the CMIE Prowess database, from 2001 to 2011. This is a rich database where a wide array of information 


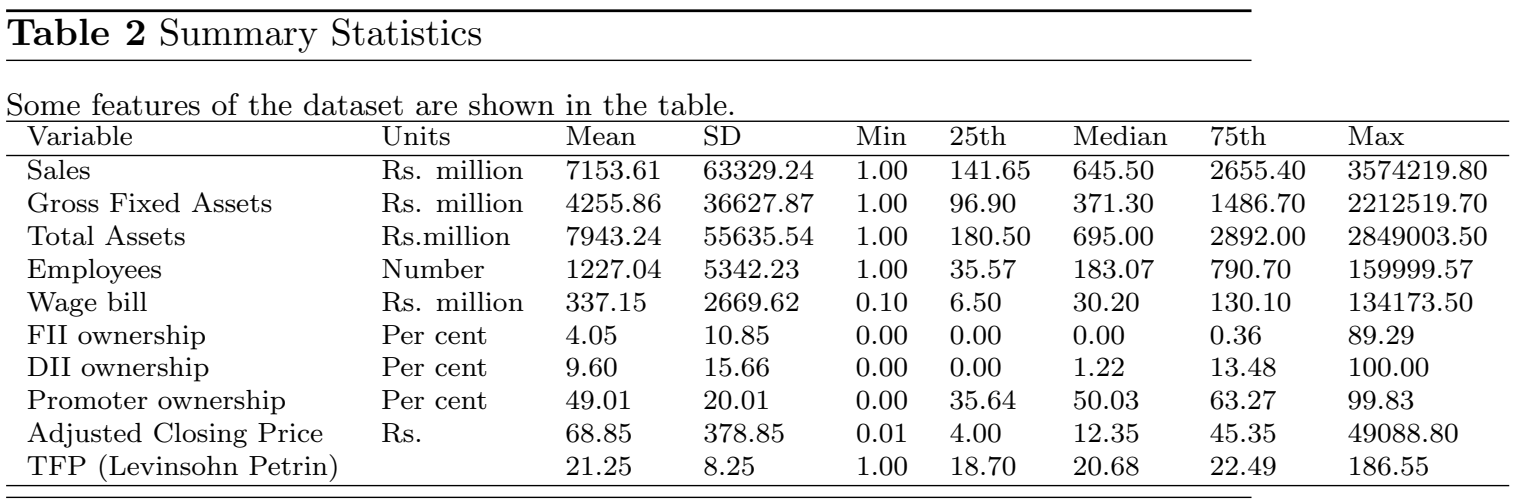

about large firms in India is observed. The industry structure of the dataset is shown in Table 1. As this table shows, the firms in our dataset are drawn from a diverse array of industries, and include many services firms also. Table 2 shows summary statistics about the firms in the dataset.

Not all firms in the CMIE database disclose the number of employees. In this paper, we have used data within a given industry within a year, to compute the average wage using firms where the number of employees was observed. This was used to impute the number of employees for observations where the overall wages was observed but the number of firms was not observed.

One simple measure of productivity is obtained by differentiating the CobbDouglas production function: $\dot{w}=\dot{y}-\alpha_{l} \dot{l}-\left(1-\alpha_{l}\right) \dot{k}$ where $\dot{w}$ is the productivity growth, $y$ is $\log$ of output, $k$ is $\log$ of capital, $l$ is log of labour and $\alpha_{l}$ is the share of labour i.e. the ratio of wages to sales.

In the estimation of firm productivity, Levinsohn and Petrin (2003) argued that there is an endogeneity problem owing to the correlation between unobservable productivity shocks and the input levels. They propose using intermediate inputs (raw material expenditure) as a proxy for the purpose of estimation. We implement their procedure using their Stata code. This procedure cannot be implemented for services firms which do not buy raw materials. Hence, when we analyse productivity using the Levinsohn-Petrin measure, we lose data for services firms.

Finally, we turn to describing categories of institutional investors observed in this dataset. Indian capital controls only permit registered 'foreign institutional investors' (FIIs) to invest in the equity market. Once registration is done, the investment process is fairly unconstrained. Three kinds of domestic institutional investors (DIIs) are present - banks, mutual funds and insurance companies. We focus on the ownership by FIIs and by DIIs.

Most firms in India have a dominant manager/shareholder, which is typically a family, which retains strategic control of the firm for very long time 
horizons. In the Indian parlance, this shareholder is termed 'the promoter'. As Table 2 shows, the median firm has promoter ownership of 50.03 per cent, i.e. full control.

Institutional investors can only choose to hold shares which are not held by the dominant shareholder. Hence, we rescale the observed shareholding by FIIs and DIIs by the total outsider shareholding. As an example, if the promoter owns $60 \%$, and if FIIs own $20 \%$, then we rescale this to $50 \%$. That is, for this firm, FIIs own half the shares traded in the public market.

The median firm in the dataset has no foreign institutional investor (FII) shareholding. At the 75th percentile, FII ownership is at $0.36 \%$. Most firms appear to be shunned by foreign investors. The median firm has just $1.22 \%$ of ownership by DIIs. At the 75th percentile, we see DII shareholding of 13.48 per cent. While this is bigger than the 75th percentile ownership of FIIs, it remains a small number. For three quarters of the firms, DIIs own below 13.48 per cent of the shares relinquished by insiders.

This raises questions about institutional ownership. What firms are chosen by FIIs and DIIs? How effective is the process of selection employed by these investors? Are institutional investors able to identify the firms with the best prospects, who would achieve high growth and stock market returns in the future? We explore these questions in the remainder of this paper.

\section{A preliminary exploration}

The first exploration that we must embark on is to examine the process of security selection of FIIs and DIIs. If, hypothetically, we find that FIIs and DIIs behave similarly, then there is no need for further exploration. As an example, Dahlquist and Robertsson (2001) find that in Sweden, while there are differences between foreign investment and domestic investment, these derive primarily through the fact that most foreign investment is institutional. When foreign institutional investors are compared against Swedish institutional investors, their preferences for firms are largely alike.

Table 3 shows that DIIs have a much bigger shareholding in top quintile companies by asset tangibility, while no strong pattern is visible with FIIs. Similarly, Table 4 shows that DIIs appear to have a lower shareholding for firms with bottom quintile values for insider shareholding.

In order to explore these relationships, we wish to estimate linear models explaining FII and DII ownership in terms of firm characteristics. Summary statistics about firm characteristics of interest are shown in Table 5. Many firms have zero values for either or both of these. Hence, we resort to Tobit 


\section{Table 3 Institutional ownership by asset tangibility}

This table breaks down the dataset into quintiles by asset tangibility, defined as the fraction of total assets which are tangible assets. In the bottom quintile, this has a median value of $14.05 \%$, while in the top quintile, this has a median value of $96.02 \%$.

In each quintile, we report the median value of FII and DII ownership. The median DII ownership is much higher $(20.33 \%)$ in the top quintile.

\begin{tabular}{llllll}
\hline & Q1 & Q2 & Q3 & Q4 & Q5 \\
\hline Tangibility & 14.05 & 34.74 & 51.10 & 69.32 & 96.02 \\
FII & 0.00 & 0.00 & 0.00 & 0.00 & 0.89 \\
DII & 0.76 & 0.27 & 1.39 & 2.92 & 20.33 \\
\hline
\end{tabular}

\section{Table 4 Institutional ownership by insider holding}

This table breaks down the dataset into quintiles by insider shareholding. Bottom quintile companies, by insider shareholding, have a median insider shareholding of $25.57 \%$. Top quintile companies, by insider shareholding, have a median insider shareholding of $73.46 \%$. In all quintiles, the median value of FII ownership is 0 . In the case of DIIs, the median value is lower for Q1 when compared with the other quintiles, i.e. DIIs appear to shun companies where a dominant shareholder has a relatively small shareholding.

\begin{tabular}{llllll}
\hline & Q1 & Q2 & Q3 & Q4 & Q5 \\
\hline Insider holding & 25.57 & 40.99 & 50.96 & 59.99 & 73.46 \\
FII & 0.01 & 0.02 & 0.02 & 0.00 & 0.00 \\
DII & 0.74 & 3.53 & 4.24 & 3.55 & 2.60 \\
\hline
\end{tabular}

\section{Table 5 Firm characteristics that may influence FII and DII ownership}

This table shows summary statistics about firm characteristics that may influence FII and DII ownership. Turnover ratio is the latest 12 month turnover expressed as a ratio of market capitalisation. The largest value, of 3.45, denotes turnover which is 3.45 times the market capitalisation. Yield is the dividend yield expressed in per cent. Total risk is the standard deviation of daily returns. Age is measured in years. Asset tangibility is the tangible assets expressed as per cent of total assets. R\&D intensity is the expense on R\&D expressed as per cent of sales.

\begin{tabular}{llllllllll}
\hline Variable & Mean & SD & Min & 25 th & Median & 75 th & Max & IQR & Observations \\
\hline Yield & 1.92 & 3.29 & 0.00 & 0.00 & 0.00 & 2.68 & 16.73 & 2.68 & 25402.00 \\
Global beta & 0.64 & 0.66 & -6.47 & 0.29 & 0.63 & 0.95 & 7.61 & 0.67 & 15250.00 \\
Total Risk & 0.85 & 0.47 & 0.26 & 0.56 & 0.72 & 0.96 & 2.86 & 0.40 & 20251.00 \\
Export-Sales ratio & 15.97 & 26.50 & 0.00 & 0.00 & 1.68 & 19.38 & 100.00 & 19.38 & 28155.00 \\
Age & 25.95 & 18.03 & 1.00 & 15.00 & 20.00 & 30.00 & 148.00 & 15.00 & 30773.00 \\
Tangibility & 63.13 & 43.77 & 1.27 & 32.38 & 56.69 & 84.51 & 244.94 & 52.12 & 29101.00 \\
R and D intensity & 0.23 & 0.89 & 0.00 & 0.00 & 0.00 & 0.00 & 6.77 & 0.00 & 28243.00 \\
\hline
\end{tabular}


Table 6 Tobit models that explain FII and DII ownership

We wish to explore the relationships between FII and DII ownership, and firm characteristics. Many firms have zero values for FII or DII investment (or both). Hence, we estimate Tobit models. Correlations within firm are addressed by clustered standard errors. Macroeconomic effects are controlled by having year fixed effects.

The table shows estimation results for a tobit model explaining FII ownership and another tobit model explaining DII ownership. Both models use the identical set of explanatory variables.

As an example, the coefficient of insider shareholding is -0.13 (with a $t$ statistic of -7.17) for the FII tobit, while it is -0.03 (with a $t$ statistic of -1.77) for the DII tobit.

\begin{tabular}{lllll}
\hline & FII & $\mathrm{t}$ & $\mathrm{DII}$ & $\mathrm{t}$ \\
\hline Insider holding & -0.13 & -7.16 & -0.02 & -1.74 \\
Log mktcap & 7.14 & 30.01 & 3.88 & 22.05 \\
Turnover ratio & 0.39 & 1.14 & -1.36 & -5.48 \\
Yield & -0.29 & -3.25 & -0.09 & -1.36 \\
Domestic beta & 3.39 & 4.61 & -0.49 & -0.97 \\
Global beta & 0.74 & 1.77 & -0.17 & -0.51 \\
Total Risk & -4.92 & -2.80 & -0.43 & -0.35 \\
Export to sales & 0.01 & 1.11 & -0.01 & -0.81 \\
Age & -0.11 & -5.72 & 0.16 & 9.39 \\
Is public sector & -6.00 & -2.76 & 10.32 & 4.52 \\
Tangibility & -0.03 & -2.94 & 0.08 & 9.06 \\
Low R and D & -0.33 & -0.59 & 1.74 & 3.43 \\
High R and D & 0.99 & 1.64 & -1.55 & -2.66 \\
\hline
\end{tabular}

models. Clustered standard errors are reported to reflect the fact that a given firm can often be observed in many years.

The results of this estimation are shown in Table 6 . In the case of FIIs, we find strong results where FIIs favour firms with reduced shareholding by insiders, bigger size, a high domestic beta, a high beta against a global index, low total risk and lower age. They avoid the dummy variable for public sector corporations. They favour reduced asset tangibility. Firms are broken into three groups by R\&D expenses - None, low and high - and three dummy variables are constructed. Of these, 'None' is the ommitted category. FIIs appear to weakly favour firms with high R\&D expenses.

The results for DIIs are strikingly different. While FIIs avoid firms with a high inside shareholding, this does not influence DIIs. The coefficient for size is much weaker: DIIs invest in smaller firms than FIIs. DIIs strongly avoid illiquid stocks while FIIs do not care about stock market liquidity. While FIIs favour domestic $\beta$ exposure, DIIs are not influenced by it, or by the global $\beta$. While FIIs avoid total risk, DIIs are not concerned about it.

Like FIIs, DIIs are not influenced by the exports/sales ratio. They strongly favour older companies, in contrast to FIIs who favour young companies. DIIs own much more public sector companies, while FIIs systematically avoid them. DIIs strongly favour firms with more tangible assets, while 


\begin{tabular}{|c|c|c|c|c|c|c|c|c|c|}
\hline \multicolumn{10}{|c|}{$\begin{array}{l}\text { This table shows summary statistics about firm characteristics of interest. As an example, } \\
\text { log market capitalisation ranged from }-1.14 \text { to } 15.07 \text { with a median value of } 5.55 \text {. }\end{array}$} \\
\hline Variable & Mean & $\mathrm{SD}$ & Min & 25 th & Median & 75 th & Max & IQR & Observations \\
\hline Domestic Beta & 0.82 & 0.50 & -2.50 & 0.54 & 0.80 & 1.07 & 5.31 & 0.53 & 15882.00 \\
\hline Log Book-to-Price & 0.11 & 1.19 & -7.06 & -0.66 & 0.14 & 0.89 & 4.61 & 1.55 & 22989.00 \\
\hline Size & 5.82 & 2.41 & -1.14 & 4.00 & 5.55 & 7.35 & 15.07 & 3.35 & 25402.00 \\
\hline Log Momentum & 1.59 & 0.09 & -0.12 & 1.56 & 1.61 & 1.62 & 2.43 & 0.06 & 28523.00 \\
\hline Turnover Ratio & 0.22 & 0.56 & 0.00 & 0.01 & 0.04 & 0.16 & 3.97 & 0.15 & 24916.00 \\
\hline
\end{tabular}

DIIs favour firms with reduced tangible assets. Finally, DIIs invest more in low R\&D companies and avoid firms that do more R\&D.

If we believe that dynamic companies are young, private, with low tangible assets, and high R\&D, then it appears that FIIs systematically favour these firms while DIIs shun them. While it may be obvious that young or private or high R\&D companies are good, they may not achieve high stock market returns or growth in the future. The information processing capabilities of an investor must be evaluated by examining the performance of firms in the period after investment date. The investment technology of an institutional investor can be evaluated in two ways: by comparing stock market returns in the future, and also by comparing the economic performance of firms in the future. However, in undertaking these comparisons, we have to be conscious of differences in asset allocation and control for these.

\section{The asset allocation of FIIs and DIIs}

The empirical asset pricing literature has emphasised factors: size (log of market capitalisation), book-to-price and $\beta$ (Fama and French, 1993). The expected returns of a portfolio tend to be higher when it tilts towards high $\beta$, low size and high book-to-price firms. Summary statistics for these firm characteristics are shown in Table $7 .^{2}$

Table 8 repeats the Tobit analysis, where the explanatory variables are quartile dummies for the size, $\mathrm{B} / \mathrm{P}$, and $\beta$. The results differ strongly, which suggests that FIIs and DIIs differ strongly in their exposure to empirical asset pricing factors. These differences need to be controlled for when examining the future performance of firms.

Figure 1 juxtaposes the exposure of FIIs and DIIs to the three asset pricing factors and Table 9 shows their median exposure from 2001 to 2011.

\footnotetext{
${ }^{2}$ We estimate the stock $\beta$ for all firms using weekly returns data for the latest two years.
} 


\section{Figure 1 Exposure to asset pricing factors}

We examine the FII and DII exposure to systematic asset pricing factors in this figure. The exposure is calculated as the weighted sum of the asset pricing factor, where the weight is equal to the funds allocated to a security as a percentage of the portfolio. For example, in a two-firm world, if the FII ownership is $w_{1}$ and $w_{2}$, market capitalisation is $m_{1}$ and $m_{2}$, and the firm beta is $b_{1}$ and $b_{2}$. Then weight of each security is $x_{1}=w_{1} m_{1} /\left(w_{1} m_{1}+w_{2} m_{2}\right)$ and the FII portfolio beta is equal to $x_{1} b_{1}+x_{2} b_{2}$.

\section{Beta}

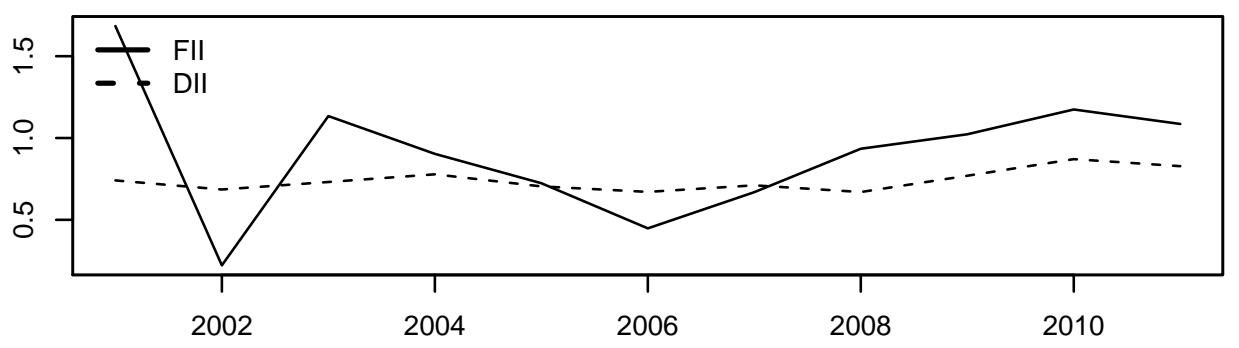

Size

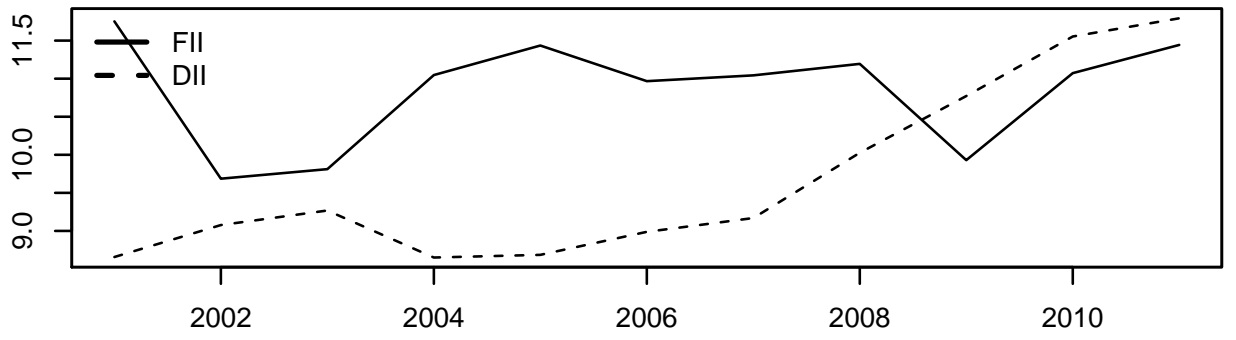

Log Book-to-price

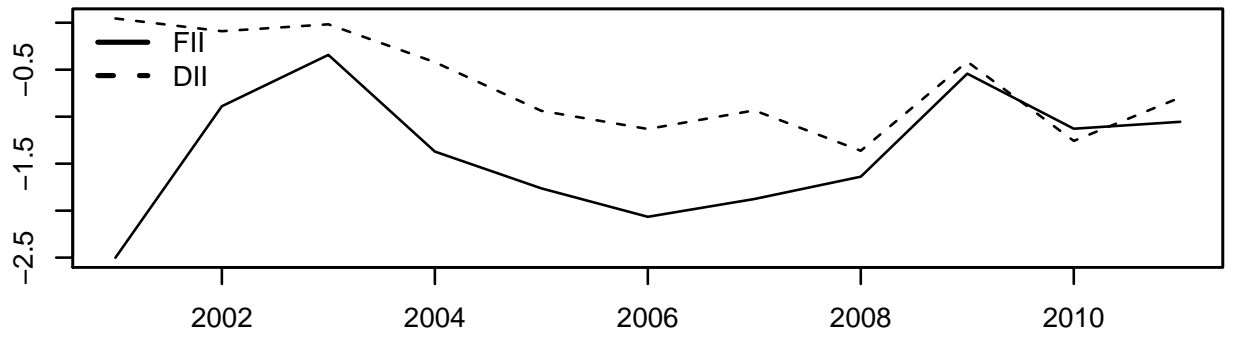


Table $\mathbf{8}$ Tobit model based on empirical asset pricing characteristics

This table shows Tobit models explaining FII and DII ownership based on empirical asset pricing factors. For each of the three factors - size, $\mathrm{B} / \mathrm{P}$ and $\beta$ - we construct four quartile dummies. The results show that FIIs and DIIs differ strongly in their asset pricing exposures.

\begin{tabular}{lllll}
\hline & FII & $\mathrm{t}$ & $\mathrm{DII}$ & $\mathrm{t}$ \\
\hline Intercept & -8.75 & -16.81 & 5.41 & 19.81 \\
Small size & 30.49 & 24.35 & 20.10 & 25.95 \\
Med size & 6.92 & 9.44 & 4.71 & 9.32 \\
Large size & 1.38 & 2.78 & 1.50 & 3.99 \\
Low Book-to-Price & 1.56 & 2.47 & 5.56 & 9.14 \\
Med Book-to-Price & 4.99 & 10.23 & 2.74 & 6.52 \\
High Book-to-Price & -0.42 & -1.14 & -0.03 & -0.10 \\
Low beta & 4.63 & 7.51 & -0.15 & -0.33 \\
Med beta & -0.85 & -1.80 & -0.10 & -0.27 \\
High beta & -0.01 & -0.02 & 0.47 & 1.51 \\
\hline
\end{tabular}

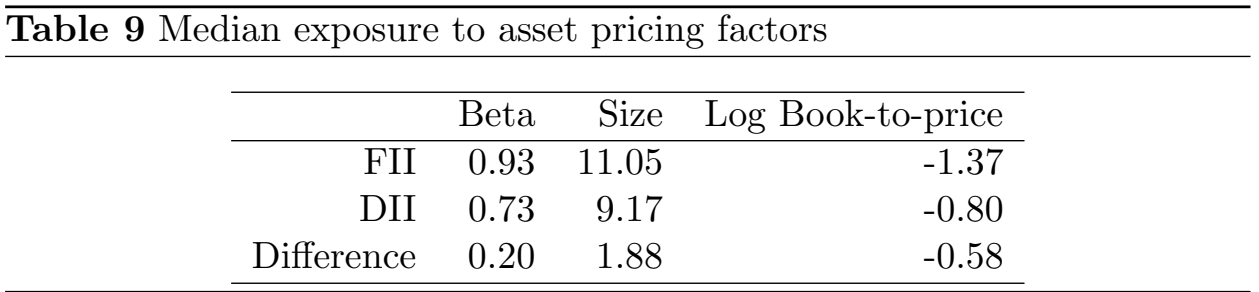

This shows substantial differences across the asset allocation of these two investors. In most years, FIIs carry a higher beta exposure than the DIIs, with a 20 points higher median exposure over our sample period. A higher beta exposure suggests higher returns. FIIs as compared to DIIs also carry a higher size exposure from 2001 to 2008, and a lower size exposure from 2009 to 2011. But the median size exposure over the sample period is higher by 1.88 points, suggeting lower returns for the FIIs. In terms of book-to-price, FIIs are exposed to low book-to-price firms in all periods with a median difference of 0.58 points. Low book to price exposure suggests lower returns.

There is a systematic difference in the asset allocation by FIIs and DIIs and this confirms the earlier argument, that these differences need to be controlled for when examining the future performance of stock returns or firm fundamentals; these may diverge owing to asset allocation and not security selection.

\section{The security selection of FIIs and DIIs}

We would like to judge the investment technology of FIIs and DIIs by evaluating the performance of firms in the future, after the date on which the 
Table 10 Number of firms in each category

The table shows the number of firms in each year, which fall into the four categories 'Both' (investment by both FIIs and DIIs that is above-median), 'High DII' (above-median investment by DIIs but below-median investment by FIIs), 'High FII' (above-median investment by FIIs but below-median investment by DIIs) and 'None' (below-median investment by both FIIs and DIIs).

\begin{tabular}{rrrrrrrrrrrr}
\hline & 2001 & 2002 & 2003 & 2004 & 2005 & 2006 & 2007 & 2008 & 2009 & 2010 & 2011 \\
\hline Both & 181 & 141 & 134 & 185 & 241 & 375 & 442 & 495 & 416 & 421 & 428 \\
High DII & 927 & 980 & 962 & 807 & 708 & 598 & 635 & 572 & 593 & 539 & 483 \\
High FII & 35 & 41 & 38 & 63 & 97 & 141 & 207 & 246 & 262 & 236 & 274 \\
None & 1319 & 1466 & 1560 & 1508 & 1547 & 1496 & 1719 & 1732 & 1769 & 1838 & 1937 \\
Sum & 2462 & 2628 & 2694 & 2563 & 2593 & 2610 & 3003 & 3045 & 3040 & 3034 & 3122 \\
\hline \hline
\end{tabular}

Table 11 Transition probabilities across the four groups of firms

Each row of this table shows probabilities for where a firm would be in year $t+1$ given that it is in a certain category in year $t$. As an example, a firm which is classified as 'None' at time $t$ would stay in that state in year $t+1$ with a probability of $94.98 \%$. There is a $2.26 \%$ per cent chance that it would jump up to 'High FII' and a $2.13 \%$ chance that it would jump up to 'High DII'. Once it goes into 'High FII' in time $t$, there is a $18.46 \%$ chance of it falling back to 'None'.

\begin{tabular}{rrrrr}
\hline & Both & High DII & High FII & None \\
\hline Both & 80.50 & 10.68 & 6.81 & 2.00 \\
High DII & 5.86 & 82.54 & 0.91 & 10.69 \\
High FII & 12.33 & 1.72 & 67.49 & 18.46 \\
None & 0.63 & 2.13 & 2.26 & 94.98 \\
\hline
\end{tabular}

shareholding pattern is observed. At the same time, we would like to control for differences in exposures to empirical asset pricing factors. This would help us assess the security selection by FIIs and DIIs, without being confounded by differences in asset allocation, i.e. systematic asset pricing factors.

We assign firm years to the following groups based on the median ownership of firms by FIIs and DIIs. We define a 'High FII' group as one where FII ownership was above $5 \%$, and DII ownership was below $6 \%$. These are the firms favoured by FIIs but disfavoured by DIIs. Similarly, we define a 'High DII' group where DII ownership was above $6 \%$, but FII ownership was below $5 \%$. Finally, a control pool is constructed of firms where neither FII nor DII ownership was above their median values (i.e. $5 \%$ for FII ownership and $6 \%$ for DII ownership). We would like to compare the future performance of a High FII company against a similar company from 'None', and the future performance of a High DII company against a similar company from 'None'.

Table 10 shows the number of firms falling into the four categories ('Both', 'High DII', 'High FII' and 'None') in each year. In 2011, there were 483 'High DII' firms and 274 'High FII' firms. There was a large number of firms in 'None', the control pool. 
Table 11 shows transition probabilities on a one year horizon across these four categories. We observe that DII investment is sticky, but FIIs change portfolio frequently. There is a strong possibility of dropping back to 'None' in year $t+1$ after being in either 'High DII' or 'High FII' category at time $t$. Once a firm is in 'High FII' category, there is an $18.46 \%$ chance that it will drop into 'None' in the next year, but there is a $12.33 \%$ chance that it will go up to 'Both' in the next year by gaining high DII investment also.

While there are significant differences between the exposures of FII and DII and seen in figure 1, it will be possible to find firms in 'None' which are similar in terms of the asset pricing factors to those seen in 'High FII' and 'High DII' groups, so as to undertake comparisons.

At the simplest, an OLS model explaining an outcome of interest $y_{i t}$ (such as stock market returns or sales growth or productivity) could control for size, $\mathrm{B} / \mathrm{P}$ and $\beta$ :

$$
y_{i, t+j}-y_{i, t-k}=\beta_{0}+\beta_{1} \text { size }_{i, t}+\beta_{2} \text { book } / \text { price }_{i, t}+\beta_{3} \text { beta }_{i, t}+\gamma^{\prime} D_{i, t}+e_{i t}
$$

In this regression, we are interested in the coefficients $\gamma$ about membership in the group 'High FII' or 'High DII' in year $t-1$. Differences between firms in size, $\mathrm{B} / \mathrm{P}$ and $\beta$. would be controlled for. We utilise information about the investment characteristics at time $t$ in order to make statements about the growth of an outcome variable $y$ from year $t-k$ to year $t+j$.

This traditional regression strategy suffers from certain weaknesses (Stuart, 2010). The impact of size, $\mathrm{B} / \mathrm{P}$ and $\beta$ upon $y$ might not be linear. When the design matrix involves some firms in 'None' and some firms in 'High FII', and their characteristics differ, the OLS regression relies upon linear extrapolation to overcome these differences. This extrapolation is fraught with difficulties. A design matrix constructed with all observations may be a poor path to sound estimates of $\gamma$.

In order to address these problems, we propose a matching-based strategy. For each firm in the 'High FII' or 'High DII' categories, we use Mahalanobis distance matching in order to find a matched partner from the 'None' category, aiming to match on size, $\mathrm{B} / \mathrm{P}$ and $\beta .^{3}$ For each of these categories, this would yield a balanced design. A caliper is used, to delete observations

\footnotetext{
${ }^{3}$ Mahalanobis distance matching in a vector of characteristics $x$ is most appropriate when $x$ is multivariate normal. While the joint distribution of size, $\mathrm{B} / \mathrm{P}$ and $\beta$ is not exactly multivariate normal, the four marginal distributions (of $\log$ size, $\log$ book-tomarket and $\beta$ ) are approximately normally distributed as seen in Figure 1. While this departure from normality is a blemish, the entire matching scheme is a means to an end: that of achieving match balance in $x$. As we show in this paper, our matching scheme (Mahalanobis distance matching with a calipers) succeeds in the sense of achieving high quality match balance.
} 


\begin{tabular}{crrr}
\hline Table 12 Number of matched pairs for high FII \\
\hline
\end{tabular}

where the match quality is poor. Matched pairs from all years are pooled to construct the dataset where OLS estimation is done:

$$
y_{i, t+j}-y_{i, t-k}=\beta_{0}+\gamma D_{i, t}+e_{i, t}
$$

We utilise information about the investment characteristics at time $t$ in order to make statements about the growth of an outcome variable $y$ from year $t-k$ to year $t+j$.

The design here is a series of matched pairs. For the firm with 'High FII', we have $D=1$, while its matched partner (which has neither high FII nor high DII investment), $D=0$. The coefficient $\gamma$ thus reports on the extent to which selection by FIIs at time $t$ impacts upon the outcome $y$.

It is also interesting to look backwards into time. The left hand side variable $y_{i, t}$ can pertain to conditions that prevailed before date $t$. In this case, the results of the regression give us insights into the process of selectivity by FIIs or DIIs. At the same time, results would be different, when compared with those obtained through the tobit regressions above, since the design matrix here is a more carefully constructed one.

Table 12 shows the results of this matching process for firms with high FII investment. As an example, in 2002, there were 41 firms with high FII investment but low DII investment, and 1466 firms with low FII investment and low DII investment. However, Mahalanobis distance matching based on size, $\mathrm{B} / \mathrm{P}$ and $\beta$ yielded only 14 matches. Overall, we see that a fairly large dataset of matched pairs is assembled using this process.

The same strategy, applied to high DII investment firms (with low FII investment) yields matched pairs as shown in Table 13. Here, a much larger number of matched pairs is obtained. 


\begin{tabular}{crrr}
\hline Table 13 Number of matched pairs for high DII & \\
\hline & Low FII, Low DII & High DII, Low FII & Matched pairs \\
\hline 2002 & 1466 & 980 & 407 \\
2003 & 1560 & 962 & 322 \\
2004 & 1508 & 807 & 236 \\
2005 & 1547 & 709 & 208 \\
2006 & 1496 & 598 & 204 \\
2007 & 1719 & 635 & 220 \\
2008 & 1732 & 572 & 219 \\
2009 & 1769 & 593 & 286 \\
2010 & 1838 & 539 & 266 \\
2011 & 1937 & 483 & 244 \\
\hline
\end{tabular}

\begin{tabular}{rrr}
\hline Table 14 Standardised Difference for FII \\
\cline { 2 - 4 } & Before Matching & After Matching \\
\cline { 2 - 4 } Size & 1.46 & 0.05 \\
Book-to-Price & -0.75 & -0.02 \\
Beta & 0.30 & 0.05 \\
\hline
\end{tabular}

\subsection{Match balance}

The first question that has to be addressed is about the extent to which this quasi-experimental strategy achieves match balance.

Table 14 shows standardised differences of size, $\mathrm{B} / \mathrm{P}$ and $\beta$ for firms with high FII investment (but low DII investment). The matching process has worked well; the standardised differences have dropped to near zero. This is reinforced by Kolmogorov-Smirnoff tests shown in Table 15. The null of equality of distributions is always rejected in the raw data and is never rejected after matching.

A similar analysis for the firms with high DII investment (but low FII investment) is shown in Table 16 and 17 . In the raw data, there are serious problems of match balance, but after matching, the standardised differences are near zero, and the null in the K-S test is not rejected.

For both kinds of institutional investors, this analysis persuades us that the matching process has resulted in a sound design. That is, we will be comparing a firm chosen by an FII or a DII against one that was not chosen by either, while ensuring that there are no systematic differences in size, $\mathrm{B} / \mathrm{P}$ and $\beta$. As emphasised earlier, this ensures that we are focused on the security analysis by FIIs and DIIs, without being clouded by their asset allocation strategies. 


\begin{tabular}{|c|c|c|}
\hline \multicolumn{3}{|c|}{ Table 15 Kolmogorov Smirnov Test for FII } \\
\hline & Before Matching & After Matching \\
\hline Size & $\begin{array}{l}0.5716 \\
(0)\end{array}$ & $\begin{array}{l}0.048 \\
(0.2194)\end{array}$ \\
\hline Book-to-Price & $\begin{array}{l}0.3061 \\
(0)\end{array}$ & $\begin{array}{l}0.0303 \\
(0.7724)\end{array}$ \\
\hline Beta & $\begin{array}{l}0.1905 \\
(0)\end{array}$ & $\begin{array}{l}0.0438 \\
(0.316)\end{array}$ \\
\hline
\end{tabular}

\begin{tabular}{rrr}
\hline Table 16 Standardised Difference for DII \\
\cline { 2 - 3 } & Before Matching & After Matching \\
\cline { 2 - 3 } & 0.50 & 0.03 \\
Size & -0.07 & 0.00 \\
Book-to-Price & 0.13 & -0.01 \\
\hline
\end{tabular}

\subsection{Firms that got high FII but low DII investment}

We now analyse the future outcomes for firms that got high FII investment, but low DII investment. These results are shown in Table 18. While conventional OLS results with all data are also shown, we focus on the quasi-experimental design obtained through matching.

The first outcome variable that we analyse is log gross fixed assets. When we look back in time, we see that the firms where $D=1$, i.e. the firms with high FII investment (but not high DII investment) got faster growth in fixed assets in the one and two years prior to observation date. In other words, FIIs appear to be choosing firms which have experienced high growth in fixed assets. Looking into the future, the firms chosen by FIIs had a change in log fixed assets that was larger than the control by 0.06 on a horizon of one year, 0.14 on a horizon of two years and 0.23 on a horizon of three years. All these differences are strongly statistically significant. This suggests that the firms chosen by FIIs increased their fixed assets strongly in the period following selection by FIIs. This could either reflect selectivity by FIIs (i.e. FIIs chose firms which were likely to grow well) and it could reflect a causal effect as well (the purchase of shares on the secondary market by FIIs impacted upon the growth of the firm).

Similar results are obtained for log total assets. FIIs chose firms where the balance sheet grew faster in the preceding one and two years. After the measurement date, the firms chosen by FIIs had a change in log total assets that was larger than the control by 0.05 on a horizon of one year, 0.1 on a horizon of two years and 0.15 on a horizon of three years. All these differences were strongly statistically significant.

Turning to employment growth, the firms chosen by FIIs had weakly superior employment growth in the years prior to measurement date. After 


\begin{tabular}{cll}
\hline Table 17 Kolmogorov Smirnov Test for DII & \\
\cline { 2 - 3 } & Before Matching & After Matching \\
\cline { 2 - 3 } Size & 0.2342 & 0.0337 \\
& $(0)$ & $(0.1031)$ \\
Book-to-Price & 0.0513 & 0.0191 \\
& $(0)$ & $(0.7249)$ \\
Beta & 0.0973 & 0.0257 \\
& $(0)$ & $(0.3566)$ \\
\hline
\end{tabular}

\section{Table 18 Outcomes for firms chosen by FIIs but not DIIs}

The dataset is a series of matched pairs, where $D=1$ is a firm with high FII investment (but low DII investment), and $D=0$ is a matched partner which got neither FII nor DII investment. Matching has been done on size, $\mathrm{B} / \mathrm{P}$ and $\beta$, and there is high quality match balance. OLS estimates for $y_{i, t}=\beta_{0}+\gamma D_{i, t-j}+e_{i, t}$ are estimated for various outcomes of interest $y$, for values of $j$, and the estimated $\hat{\gamma}$ is reported in each case. Clustered robust standard errors are reported. While the main focus is on the matching-based estimates, conventional OLS estimates using unfiltered data are also reported.

As an example, consider an outcome of interest: log total assets. The matching based estimate shows that the firms chosen by FIIs have a change in log total assets over a three year horizon that is larger than that observed for controls by 0.15 , with a standard error of 0.047 .

\begin{tabular}{|c|c|c|}
\hline \multicolumn{3}{|c|}{ Log Gross Fixed Assets } \\
\hline & OLS & Matching \\
\hline$X_{t}-X_{t-2}$ & $0.08(0.033) *$ & $0.11(0.036) * *$ \\
\hline$X_{t}-X_{t-1}$ & $0.04(0.02) *$ & $0.06(0.021) * *$ \\
\hline$X_{t+1}-X_{t}$ & $0.06(0.021) * *$ & $0.06(0.018) * *$ \\
\hline$X_{t+2}-X_{t}$ & $0.08(0.033) *$ & $0.14(0.039) * * *$ \\
\hline$X_{t+3}-X_{t}$ & $0.12(0.044) * *$ & $0.23(0.057) * * *$ \\
\hline \multicolumn{3}{|c|}{ Log Employment } \\
\hline & OLS & Matching \\
\hline$X_{t}-X_{t-2}$ & $0.17(0.044) * * *$ & $0.1(0.038) *$ \\
\hline$X_{t}-X_{t-1}$ & $0.11(0.025) * * *$ & $0.05(0.022) *$ \\
\hline$X_{t+1}-X_{t}$ & $0.02(0.024)$ & $0.03(0.022)$ \\
\hline$X_{t+2}-X_{t}$ & $0.07(0.047)$ & $0.07(0.044)$ \\
\hline$X_{t+3}-X_{t}$ & $0.07(0.067)$ & $0.11(0.069)$ \\
\hline
\end{tabular}

\begin{tabular}{lll}
\multicolumn{3}{c}{ Log Total Assets } \\
\hline & OLS & Matching \\
\hline$X_{t}-X_{t-2}$ & $0.15(0.036) * * *$ & $0.1(0.027) * * *$ \\
$X_{t}-X_{t-1}$ & $0.1(0.02) * * *$ & $0.05(0.014) * * *$ \\
$X_{t+1}-X_{t}$ & $0.08(0.019) * * *$ & $0.05(0.014) * *$ \\
$X_{t+2}-X_{t}$ & $0.11(0.031)^{* * *}$ & $0.1(0.029) * *$ \\
$X_{t+3}-X_{t}$ & $0.13(0.043)^{* *}$ & $0.15(0.047)^{* *}$ \\
\hline
\end{tabular}

\begin{tabular}{lll}
\multicolumn{3}{c}{ Log Sales } \\
\hline & OLS & Matching \\
\hline$X_{t}-X_{t-2}$ & $0.04(0.033)$ & $0.03(0.042)$ \\
$X_{t}-X_{t-1}$ & $0.03(0.018)$. & $0.02(0.024)$ \\
$X_{t+1}-X_{t}$ & $0.06(0.021) * *$ & $0.03(0.025)$ \\
$X_{t+2}-X_{t}$ & $0.11(0.041) * *$ & $0.04(0.046)$ \\
$X_{t+3}-X_{t}$ & $0.2(0.064)^{* *}$ & $0.16(0.07) *$ \\
\hline
\end{tabular}

Cobb Douglas Productivity Growth

\begin{tabular}{lll}
\hline & OLS & Matching \\
\hline$X_{t}-X_{t-2}$ & $0.05(0.033)$ & $-0.06(0.027)^{*}$ \\
$X_{t}-X_{t-1}$ & $0.09(0.056)$ & $-0.11(0.045) *$ \\
$X_{t+1}-X_{t}$ & $0.01(0.028)$ & $-0.03(0.03)$ \\
$X_{t+2}-X_{t}$ & $0.05(0.049)$ & $-0.09(0.055)$ \\
$X_{t+3}-X_{t}$ & $0.07(0.069)$ & $-0.05(0.075)$ \\
\hline
\end{tabular}

\begin{tabular}{|c|c|c|}
\hline \multicolumn{3}{|c|}{ TFP (Log LP estimate) } \\
\hline & OLS & Matching \\
\hline$X_{t}-X_{t-2}$ & $-0.01(0.016)$ & $0(0.01)$ \\
\hline$X_{t}-X_{t-1}$ & $0(0.008)$ & $0(0.006)$ \\
\hline$X_{t+1}-X_{t}$ & $-0.01(0.01)$ & $-0.01(0.007)$ \\
\hline$X_{t+2}-X_{t}$ & $0.01(0.012)$ & $-0.01(0.012)$ \\
\hline$X_{t+3}-X_{t}$ & $0.01(0.013)$ & $0(0.016)$ \\
\hline
\end{tabular}

\begin{tabular}{|c|c|c|}
\hline \multicolumn{3}{|c|}{ Log Adjusted Closing Price } \\
\hline & OLS & Matching \\
\hline$X_{t}-X_{t-2}$ & $0.21(0.092) *$ & $-0.05(0.057)$ \\
\hline$X_{t}-X_{t-1}$ & $0.19(0.06) * *$ & $-0.01(0.035)$ \\
\hline$X_{t+1}-X_{t}$ & $0.01(0.07)$ & $-0.04(0.038)$ \\
\hline$X_{t+2}-X_{t}$ & $-0.08(0.106)$ & $-0.11(0.069)$ \\
\hline$X_{t+3}-X_{t}$ & $-0.09(0.128)$ & $-0.12(0.103)$ \\
\hline
\end{tabular}


the measurement date, their employment growth was only slightly greater than the control. The firms chosen by FIIs thus appear to have pursued capital-intensive growth strategies in the years after measurement date.

Despite strong increases in capital, and slight increases in employment, on a horizon of one and two years after measurement date, output growth by selected firms was not significantly greater than the control.

A simple productivity measure as described above yields striking and negative estimates. The firms chosen by FIIs were inferior compared with the control in the two years prior to measurement date. This reflects the combination of high growth of capital but weak growth in output.

For manufacturing firms, we are able to compare TFP using LevinsohnPetrin estimates. This shows no statistically significant difference between the firms chosen by FIIs and the controls.

Finally, we look at stock market returns. Firms chosen by FIIs show a signicantly lesser return than the controls over a two and three year horizon.

To summarise, these results suggest that the firms chosen by FIIs are on a trajectory of capital deepening. In the period after measurement date, there is strong growth of capital when compared with the control, which could either reflect forecasts of high growth by the FII, or a causal effect of the purchase of shares by FIIs. There is weak evidence of increased employment. However, the impact of output, productivity and stock market returns is surprisingly weak. On horizons of one, two and three years, it is hard to suggest that the firms chosen by FIIs fared better than the controls, either in terms of returns or in terms of growth in output and employment.

\subsection{Firms that got high DII but low FII investment}

We now turn to the firms chosen by DIIs but not FIIs, where results are in Table 19. In the years prior to the measurement date, the firms selected by DIIs had lower growth in fixed assets and in total assets. In the years after measurement date, their growth of capital is not statistically significantly different from the control. This may be interpreted as investing in distressed companies.

With employment and output, there is no difference between the firms chosen by DIIs and the controls, in the period before measurement date. But in terms of output growth, firms chosen by DIIs experience higher growth at a three year horizon.

When we examine the simple measure of productivity growth on a three year horizon, the firms chosen by DIIs outperform the controls by a factor 


\section{Table 19 Outcomes for firms chosen by DIIs but not FIIs}

The dataset is a series of matched pairs, where $D=1$ is a firm with high DII investment (but low FII investment), and $D=0$ is a matched partner which got neither FII nor DII investment. Matching has been done on size, $\mathrm{B} / \mathrm{P}$ and $\beta$, and there is high quality match balance. OLS estimates for $y_{i, t}=\beta_{0}+\gamma D_{i, t-j}+e_{i, t}$ are estimated for various outcomes of interest $y$, for values of $j$, and the estimated $\hat{\gamma}$ is reported in each case. Clustered robust standard errors are reported. While the main focus is on the matching-based estimates, conventional OLS estimates using unfiltered data are also reported.

As an example, consider an outcome of interest: log total assets. The matching based estimate shows that the firms chosen by DIIs have a change in log total assets two years prior to measurement date that is larger than that observed for controls by -0.06 , with a standard error of 0.015 .

\begin{tabular}{|c|c|c|c|c|c|}
\hline \multicolumn{3}{|c|}{ Log Gross Fixed Assets } & \multicolumn{3}{|c|}{ Log Total Assets } \\
\hline & OLS & Matching & \multicolumn{2}{|c|}{ OLS } & Matching \\
\hline$X_{t}-X_{t-2}$ & $-0.1(0.02) * * *$ & $-0.05(0.02) *$ & $X_{t}-X_{t-2}$ & \multirow{2}{*}{$\begin{array}{l}-0.1(0.018) * * * \\
-0.04(0.01)\end{array} * * *$} & $-0.06(0.015))^{* * *}$ \\
\hline$X_{t}-X_{t-1}$ & $-0.05(0.011) * * *$ & $-0.02(0.01)$ & $X_{t}-X_{t-1}$ & & $-0.01(0.008)$ \\
\hline$X_{t+1}-X_{t}$ & $-0.03(0.01) *$ & $-0.01(0.012)$ & $X_{t+1}-X_{t}$ & $-0.01(0.01)$ & $-0.01(0.009)$ \\
\hline$X_{t+2}-X_{t}$ & $-0.05(0.02) * *$ & $-0.02(0.023)$ & $X_{t+2}-X_{t}$ & $-0.02(0.018)$ & $-0.02(0.017)$ \\
\hline$X_{t+3}-X_{t}$ & $-0.05(0.031)$ & $-0.04(0.033)$ & $X_{t+3}-X_{t}$ & $-0.01(0.026)$ & $-0.02(0.025)$ \\
\hline \multicolumn{3}{|c|}{ Log Employment } & \multicolumn{3}{|c|}{ Log Sales } \\
\hline & OLS & Matching & & OLS & Matching \\
\hline$X_{t}-X_{t-2}$ & $-0.06(0.024) * *$ & $-0.02(0.021)$ & $X_{t}-X_{t-2}$ & $-0.05(0.021) *$ & $0(0.025)$ \\
\hline$X_{t}-X_{t-1}$ & $-0.03(0.013) *$ & $0(0.013)$ & $X_{t}-X_{t-1}$ & $-0.02(0.012)$ & $0.01(0.015)$ \\
\hline$X_{t+1}-X_{t}$ & $-0.03(0.015)$ & $0.01(0.013)$ & $X_{t+1}-X_{t}$ & $0.01(0.015)$ & $0(0.017)$ \\
\hline$X_{t+2}-X_{t}$ & $-0.03(0.026)$ & $-0.02(0.024)$ & $X_{t+2}-X_{t}$ & $0.03(0.028)$ & $0.01(0.032)$ \\
\hline$X_{t+3}-X_{t}$ & $-0.01(0.036)$ & $-0.04(0.035)$ & $X_{t+3}-X_{t}$ & $0.05(0.04)$ & $0.06(0.044)$ \\
\hline \multicolumn{3}{|c|}{ Cobb Douglas Productivity Growth } & \multicolumn{3}{|c|}{ TFP (Log LP estimate) } \\
\hline & OLS & Matching & & OLS & Matching \\
\hline$X_{t}-X_{t-2}$ & $0.02(0.018)$ & $0.02(0.016)$ & $X_{t}-X_{t-2}$ & $0(0.007)$ & $0(0.006)$ \\
\hline$X_{t}-X_{t-1}$ & $0.05(0.03)$ & $0.04(0.026)$ & $X_{t}-X_{t-1}$ & $0(0.005)$ & $0(0.004)$ \\
\hline$X_{t+1}-X_{t}$ & $0.03(0.018)$ & $0(0.017)$ & $X_{t+1}-X_{t}$ & $0.01(0.005)$ & $0(0.004)$ \\
\hline$X_{t+2}-X_{t}$ & $0.09(0.031) * *$ & $0.03(0.031)$ & $X_{t+2}-X_{t}$ & $0.02(0.006) *$ & $0.01(0.006)$ \\
\hline$X_{t+3}-X_{t}$ & $0.13(0.043) * *$ & $0.08(0.042) *$ & $X_{t+3}-X_{t}$ & $0.01(0.008)$ & $0.01(0.01)$ \\
\hline \multicolumn{3}{|c|}{ Log Adjusted Closing Price } & & & \\
\hline & OLS & Matching & & & \\
\hline$X_{t}-X_{t-2}$ & $0.05(0.052)$ & $0.03(0.035)$ & & & \\
\hline$X_{t}-X_{t-1}$ & $0.06(0.03)$ & $0.04(0.021)$ & & & \\
\hline$X_{t+1}-X_{t}$ & $0.17(0.034) * * *$ & $0.07(0.023) * *$ & & & \\
\hline$X_{t+2}-X_{t}$ & $0.25(0.053) * * *$ & $0.12(0.038) * *$ & & & \\
\hline$X_{t+3}-X_{t}$ & $0.26(0.066) * * *$ & $0.18(0.057)^{* *}$ & & & \\
\hline
\end{tabular}


of 0.08 , which is statistically significant at a 95 per cent level. However, when this is repeated within manufacturing firms only using the Levinsohn-Petrin measure of TFP, the differences in productivity is 0.01 .

The most interesting results are found with stock market returns. On horizons of one, two and three years, the firms chosen by DIIs outperform the controls. The superior returns are economically significant: 7 per cent on a one year horizon (with a standard error of 2.3 percentage points), 12 per cent on a two year horizon (with a standard error of 3.8 percentage points) and 18 per cent on a three year horizon (with a standard error of 5.7 percentage points).

The firms chosen by DIIs yield superior stock market returns when compared with controls, while the firms chosen by FIIs do not. This suggests that DIIs possess a valuable investment technology while FIIs do not. While the firms that FIIs invest in experience exuberant growth, there are concerns about productivity, and superior stock market returns are not obtained. In contrast, DIIs appear to get involved in firms that are experiencing difficulties. However, there is some evidence of gains in productivity and strong evidence about superior stock market returns.

\section{Sensitivity analyses}

We assess the robustness of these results by undertaking three alternative estimations.

1. Size weights

2. More extreme definitions of FII and DII

3. Alternative choices of asset pricing factors

\section{$7.1 \quad$ Size weights}

The main results shown in the paper treated all firms as equal. This may give undue importance to a large number of small firms. Hence, we undertake the same analysis with size weights. Size is defined as the average of firm sales and firm total assets.

The results for firms with high FII investment (but not high DII investment) are presented in Table 21 in the appendix. As with the main results, firms chosen by FIIs (but not DIIs) experience rapid growth of capital, prior to the measurement year and after it. While there is improvement in employment growth on a horizon of one year, this does not take place over two and three year horizons. However, this is associated with inferior productivity growth. 
The coefficients at all horizons are negative but not statistically significant. There is no evidence of superior stock market returns.

Size-weighted results for firms with high DII investment (but not high FII investment) are presented in Table 22 in the appendix. These are also qualitatively similar to the main results. These firms have experienced declining total assets for the years prior to measurement date and both one and three years after measurement date. Employment and output growth appear to be no different from the control prior to measurement date, though they are significantly lesser than the control firm over a horizon of two and three years. However, there is strong evidence of superior productivity growth. There is also strong evidence of superior stock market returns by $15 \%$ on a one year horizon and $21 \%$ on a two year horizon. This suggests that DIIs have impressive investment technology while FIIs do not.

\subsection{More extreme definitions for FII and DII dummies}

The main results of the paper were based on median values for FII and DII investment of five and six per cent respectively. That is, a "High FII investment" firm was defined as one with more than $5 \%$ ownership of nonpromoter shares by FIIs.

We redo the calculations using a more extreme definition. We define a High FII group as one where FII ownership was above $12.5 \%$ (i.e. 66 th percentile of the distribution of FII investment), and DII ownership was below $1.35 \%$ (i.e. 33rd percentile of the distribution of DII investment). Similarly, we define a High DII group where DII ownership was above $18.6 \%$, but FII ownership was below $3.23 \%$. The control group is constructed of firms where neither FII nor DII ownership was above their 33rd percentile values.

Table 23, in the appendix, shows the results for firms with high FII investment (but low DII investment). These results are qualitatively similar to the main findings of the paper. The firms chosen by FIIs have experienced strong growth in capital prior to measurement date, and also see strong capital growth after measurement date. Employment growth is also superior, as is sales growth.

However, the productivity measures show that the chosen firms have inferior productivity growth when compared with the controls. The stock market returns obtained by these firms is sharply inferior to that obtained by the controls over horizons of one, two and three years.

Turning to the firms chosen for high investment by DIIs (but not FIIs), the results (Table 24 in the appendix) show that DIIs choose firms where total assets have declined over the recent two years. Employment growth is 
Figure 2 Exposure to Turnover Ratio and Momentum

This figure shows the FII and DII exposure in terms of turnover ratio and momentum. The calculation is done as described in figure 1 .

\section{Log Turnover Ratio}

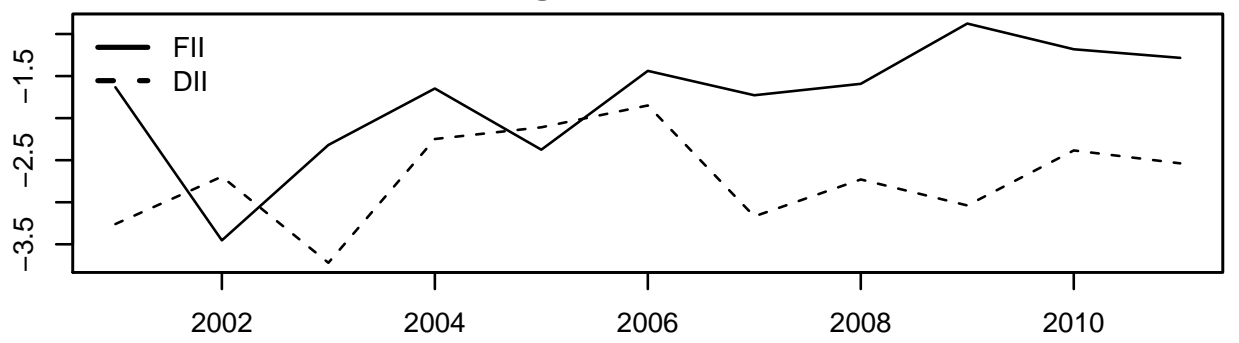

Log Momentum

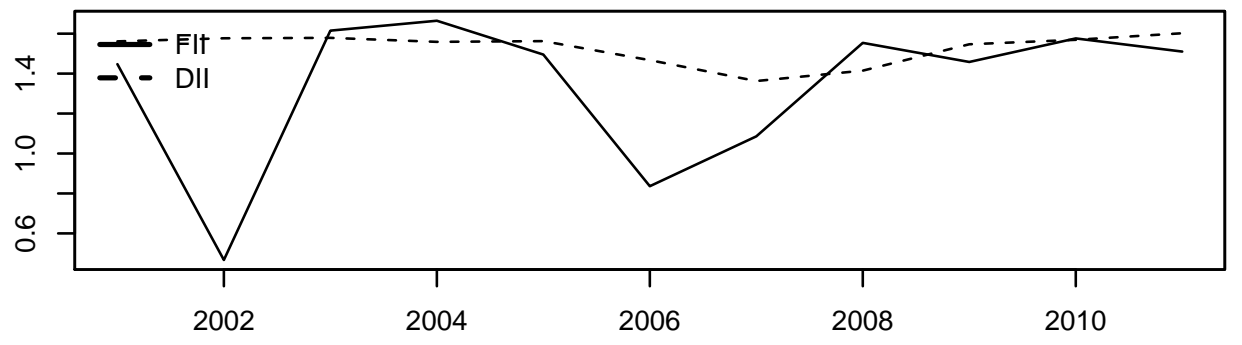

Table 20 Median exposure to Turnover Ratio and Momentum

\begin{tabular}{rrr}
\hline & Log Momentum & Log Turnover Ratio \\
\hline FII & 1.50 & -1.63 \\
DII & 1.56 & -2.70 \\
Difference & -0.07 & 1.06
\end{tabular}

reduced over the horizons of three years. Output growth is no different from the controls. The null of no difference cannot be rejected for stock market returns.

\subsection{Alternative choices of asset pricing factors}

The main results of the paper were based on matching the securities selected by FIIs and DIIs on the basis of the three asset pricing factors: Size, B/P, and $\beta$. Below, we redo the calculations by matching firms on two additional variables: Liquidity of the stock measured by the turnover ratio, and momentum measured as the six month return of the stock. 


\subsubsection{Liquidity}

Figure 2 and table 20 show that FIIs invest in more liquid stocks as compared to DIIs. The median FII exposure is greater by 1.06 points than the median DII exposure, further highlighting the difference in asset allocation by these two types of investors.

Table 25 in the appendix, shows the results for firms with high FII investment (but low DII investment). The firms chosen by FIIs have experienced strong growth in capital prior to measurement date, and also see strong capital growth after measurement date. Employment growth is not significantly different from the controls, but output growth over a horizon of three years, is higher than the controls. However, the simple measure of productivity shows that the chosen firms have inferior productivity growth when compared with the controls prior to measurement date. The stock market returns obtained by these firms is lesser than that obtained by the controls but are not statistically significant.

Table 26 in the appendix, shows the results for firms with high DII investment and low FII investment. DIIs choose firms where total assets have declined over the recent two years. Employment growth and output growth are no different from the controls. However, both the measures of productivity show that the firms chosen by DIIs have superior productivity growth over a horizon of three years. The stock market returns of firms chosen by DIIs are sharply superior to that obtained by the controls over a horizon of one, two and three years. Thus the results with controlling for liquidity are qualitatively similar to the results main results of the paper.

\subsubsection{Momentum}

Momentum is an important idea in the asset pricing literature (Jegadeesh and Titman, 1993; Desai, Ramesh, Thiagarajan, and Balachandran, 2002). As figure 2 shows, there is no important difference between FIIs and DIIs on the momentum factor. The median difference in exposure is only 0.07 as shown in table 20 . Hence, the analysis of security selection after controlling for four asset pricing factors - B/M, size, beta, momentum - would be no different from the analysis with the three Fama-French factors as shown in Section 6 .

\section{Conclusions}

This paper brings a fresh perspective in understanding the role of foreign and domestic institutional investors. The striking feature in the data is 
the fact that large numbers of firms obtain neither FII nor DII investment. There are strong differences between the characteristics of firms chosen by FIIs as opposed to the firms chosen by DIIs.

This encourages the question: Do FIIs and DIIs do well in choosing certain firms for investment? How do the chosen firms perform in the future, in terms of financial returns, and in terms of economic outcomes such as growth in output and productivity? A quasi-experimental opportunity to identify the differences between FIIs and DIIs is created by identifying firms which have high FII investment (but low DII investment) and vice versa. If either FIIs or DIIs have skills in identifying firms that will do well, or if their decision to invest in a firm has a causal impact upon the future trajectory of the firm, then the chosen firms will fare well in the future.

We emphasise the distinction between asset allocation and security selection. There are systematic differences between FIIs, DIIs and controls in the size, $\mathrm{B} / \mathrm{P}$ and $\beta$. These differences in asset allocation need to be controlled for so as to focus on the investment technology of security selection. As an example, if FIIs systematically invest in high beta firms, and high beta firms do well in a business cycle expansion, it will appear that FIIs have the ability to pick winners under buoyant business cycle conditions.

We propose a matching-based strategy in order to address this problem. Each firm that is chosen by FIIs (but not DIIs) is matched to a control (that was chosen by neither FII nor DII) based on size, $\mathrm{B} / \mathrm{P}$ and $\beta$. The comparison of future outcomes, between the firm that was chosen and the control, identifies the security selection prowess of the institutional investor.

The results suggest that the firms chosen by FIIs are those that have experienced high growth of capital (when compared with the control) prior to the observation date. They continue to obtain high growth of capital after the observation date. There is some evidence of superior output growth. However, the chosen firms appear to have inferior productivity growth, and deliver inferior stock market returns when compared with the controls. These results suggest that FIIs do not possess a valuable investment technology.

In contrast, the firms chosen by DIIs appear to deliver superior returns in the years after measurement date. This suggests that DIIs possess a valuable investment technology. The firms chosen by DIIs appear to be distressed firms. They tend to have reduced growth of capital both prior to observation date in the years thereafter. The chosen firms appear to have superior productivity growth in the years after observation date.

If large corporations in India were financially constrained, then firms with institutional investment would be expected to have sharp growth of assets, and to be able to deploy capital into high quality projects. However, the results show that firms chosen by DIIs do not increase capital, and while 
firms chosen by FIIs do experience capital growth, this may go with reduced productivity. The results are, thus, not consistent with the notion that large corporations in India have high quality projects but suffer from financing constraints.

The contribution of this paper lies in two respects. First, these results illuminate the role of foreign and domestic institutional investors in one large emerging market, India. Second, many elements of the measurement strategy used in this paper are applicable more generally. The distinction between asset allocation and security selection, and the quasi-experimental measurement strategy based on matching on size, $\mathrm{B} / \mathrm{P}$ and $\beta$, could be applied in other settings. Extending this strategy to databases in other emerging markets would constitute one interesting area for future research.

Our results raise difficult questions. If FIIs do not possess a superior investment technology, would they be better off with investment strategies such as investing in index funds or in sub-contracting their investment process to DIIs? This raises questions about the incentives and contracts in financial intermediation that leads to foreign investment, which could be usefully explored in future research. 


\section{Appendix}

Table 21 Outcomes for firms chosen by FIIs but not DIIs: Size weighted

\begin{tabular}{|c|c|c|c|c|c|}
\hline \multicolumn{3}{|c|}{ Log Gross Fixed Assets } & \multicolumn{3}{|c|}{ Log Total Assets } \\
\hline & OLS & Matching & \multicolumn{2}{|r|}{ OLS } & Matching \\
\hline$X_{t}-X_{t-2}$ & $0.28(0.169)$ & $0.2(0.05) * * *$ & $X_{t}-X_{t-2}$ & $0.3(0.074) * * *$ & $0.15(0.031) * * *$ \\
\hline$X_{t}-X_{t-1}$ & $0.2(0.149)$ & $0.12(0.03) * * *$ & $X_{t}-X_{t-1}$ & $0.14(0.046) * *$ & $0.07(0.017) * * *$ \\
\hline$X_{t+1}-X_{t}$ & $0.15(0.089)$ & $0.09(0.031) * *$ & $X_{t+1}-X_{t}$ & $0.1(0.031) * *$ & $0.07(0.016) * * *$ \\
\hline$X_{t+2}-X_{t}$ & $0.06(0.121)$ & $0.16(0.046) * * *$ & $X_{t+2}-X_{t}$ & $0.14(0.051) * *$ & $0.11(0.043) * *$ \\
\hline$X_{t+3}-X_{t}$ & $0.06(0.173)$ & $0.16(0.066) *$ & $X_{t+3}-X_{t}$ & $0.17(0.066) * *$ & $0.13(0.066) *$ \\
\hline \multicolumn{3}{|c|}{ Log Employment } & \multicolumn{3}{|c|}{ Log Sales } \\
\hline & OLS & Matching & & OLS & Matching \\
\hline$\overline{X_{t}-X_{t-2}}$ & $0.22(0.116)$ & $0.37(0.199)$ & $X_{t}-X_{t-2}$ & $-0.16(0.099)$ & $0.08(0.047)$. \\
\hline$X_{t}-X_{t-1}$ & $0.12(0.039) * *$ & $0.25(0.154)$ & $X_{t}-X_{t-1}$ & $0.11(0.109)$ & $0.01(0.044)$ \\
\hline$X_{t+1}-X_{t}$ & $0.01(0.028)$ & $0.07(0.023) * *$ & $X_{t+1}-X_{t}$ & $0.05(0.054)$ & $0.06(0.026) *$ \\
\hline$X_{t+2}-X_{t}$ & $0.01(0.063)$ & $0.04(0.059)$ & $X_{t+2}-X_{t}$ & $-0.01(0.054)$ & $0.13(0.055) *$ \\
\hline$X_{t+3}-X_{t}$ & $-0.03(0.077)$ & $-0.01(0.084)$ & $X_{t+3}-X_{t}$ & $0.04(0.109)$ & $0.24(0.075) * *$ \\
\hline \multicolumn{3}{|c|}{ Cobb Douglas Productivity Growth } & \multicolumn{3}{|c|}{ TFP (Log LP estimate) } \\
\hline & OLS & Matching & & OLS & Matching \\
\hline$X_{t}-X_{t-2}$ & $0.09(0.037) *$ & $-0.11(0.063)$ & $X_{t}-X_{t-2}$ & $-0.01(0.019)$ & $-0.02(0.022)$ \\
\hline$X_{t}-X_{t-1}$ & $0.2(0.08) *$ & $-0.14(0.083)$ & $X_{t}-X_{t-1}$ & $-0.01(0.014)$ & $-0.02(0.017)$ \\
\hline$X_{t+1}-X_{t}$ & $0.02(0.034)$ & $-0.05(0.038)$ & $X_{t+1}-X_{t}$ & $0(0.013)$ & $-0.02(0.015)$ \\
\hline$X_{t+2}-X_{t}$ & $0.02(0.074)$ & $-0.03(0.078)$ & $X_{t+2}-X_{t}$ & $0.01(0.015)$ & $-0.02(0.025)$ \\
\hline$X_{t+3}-X_{t}$ & $0.08(0.099)$ & $0.1(0.121)$ & $X_{t+3}-X_{t}$ & $0.02(0.022)$ & $0.01(0.028)$ \\
\hline \multicolumn{3}{|c|}{ Log Adjusted Closing Price } & & & \\
\hline & OLS & Matching & & & \\
\hline$X_{t}-X_{t-2}$ & $0.45(0.133) * * *$ & $0.15(0.108)$ & & & \\
\hline$X_{t}-X_{t-1}$ & $0.26(0.099) * *$ & $0.04(0.051)$ & & & \\
\hline$X_{t+1}-X_{t}$ & $0.01(0.109)$ & $0.01(0.059)$ & & & \\
\hline$X_{t+2}-X_{t}$ & $-0.07(0.24)$ & $0.05(0.115)$ & & & \\
\hline$X_{t+3}-X_{t}$ & $-0.21(0.301)$ & $-0.11(0.166)$ & & & \\
\hline
\end{tabular}


Table 22 Outcomes for firms chosen by DIIs but not FIIs: Size weighted

\begin{tabular}{|c|c|c|c|c|c|}
\hline \multicolumn{3}{|c|}{ Log Gross Fixed Assets } & \multicolumn{3}{|c|}{ Log Total Assets } \\
\hline & OLS & Matching & & OLS & Matching \\
\hline$X_{t}-X_{t-2}$ & $-0.05(0.04)$ & $-0.24(0.169)$ & $X_{t}-X_{t-2}$ & $-0.03(0.045)$ & $-0.07(0.024) * *$ \\
\hline$X_{t}-X_{t-1}$ & $-0.03(0.022)$ & $0(0.017)$ & $X_{t}-X_{t-1}$ & $-0.01(0.028)$ & $-0.04(0.015) * *$ \\
\hline$X_{t+1}-X_{t}$ & $-0.04(0.023)$. & $-0.01(0.015)$ & $X_{t+1}-X_{t}$ & $-0.01(0.023)$ & $-0.04(0.017) *$ \\
\hline$X_{t+2}-X_{t}$ & $-0.17(0.098)$. & $-0.05(0.037)$ & $X_{t+2}-X_{t}$ & $-0.04(0.035)$ & $-0.06(0.032)$ \\
\hline$X_{t+3}-X_{t}$ & $-0.21(0.15)$ & $-0.12(0.059) *$ & $X_{t+3}-X_{t}$ & $-0.04(0.048)$ & $-0.1(0.049) *$ \\
\hline \multicolumn{3}{|c|}{ Log Employment } & \multicolumn{3}{|c|}{ Log Sales } \\
\hline & OLS & Matching & & OLS & Matching \\
\hline$X_{t}-X_{t-2}$ & $-0.01(0.058)$ & $0.13(0.134)$ & $X_{t}-X_{t-2}$ & $-0.24(0.148)$ & $-0.3(0.252)$ \\
\hline$X_{t}-X_{t-1}$ & $-0.01(0.019)$ & $0.14(0.109)$ & $X_{t}-X_{t-1}$ & $-0.01(0.018)$ & $-0.01(0.023)$ \\
\hline$X_{t+1}-X_{t}$ & $-0.03(0.025)$ & $0.12(0.123)$ & $X_{t+1}-X_{t}$ & $0.02(0.024)$ & $0.01(0.017)$ \\
\hline$X_{t+2}-X_{t}$ & $-0.07(0.042)$ & $-0.07(0.035)$ & $X_{t+2}-X_{t}$ & $0(0.075)$ & $0.09(0.051)$ \\
\hline$X_{t+3}-X_{t}$ & $-0.06(0.057)$ & $-0.1(0.051)$ & $X_{t+3}-X_{t}$ & $-0.08(0.143)$ & $0.15(0.078)$. \\
\hline \multicolumn{3}{|c|}{ Cobb Douglas Productivity Growth } & \multicolumn{3}{|c|}{ TFP ( Log Log LP estimate) } \\
\hline & OLS & Matching & & OLS & Matching \\
\hline$X_{t}-X_{t-2}$ & $0.09(0.031)^{* *}$ & $-0.02(0.033)$ & $X_{t}-X_{t-2}$ & $0.01(0.012)$ & $0(0.009)$ \\
\hline$X_{t}-X_{t-1}$ & $0.14(0.048) * *$ & $-0.09(0.097)$ & $X_{t}-X_{t-1}$ & $0.01(0.008)$ & $0(0.006)$ \\
\hline$X_{t+1}-X_{t}$ & $0.07(0.029) *$ & $0(0.021)$ & $X_{t+1}-X_{t}$ & $0.02(0.011) *$ & $0(0.009)$ \\
\hline$X_{t+2}-X_{t}$ & $0.12(0.046) * *$ & $0.11(0.051) *$ & $X_{t+2}-X_{t}$ & $0.04(0.013) * *$ & $0.03(0.014) *$ \\
\hline$X_{t+3}-X_{t}$ & $0.16(0.055) * *$ & $0.24(0.079) * *$ & $X_{t+3}-X_{t}$ & $0.04(0.013) * *$ & $0.06(0.02) * *$ \\
\hline \multicolumn{3}{|c|}{ Log Adjusted Closing Price } & & & \\
\hline & OLS & Matching & & & \\
\hline$X_{t}-X_{t-2}$ & $0.17(0.082) *$ & $0.07(0.049)$ & & & \\
\hline$X_{t}-X_{t-1}$ & $0.12(0.056) *$ & $-0.02(0.046)$ & & & \\
\hline$X_{t+1}-X_{t}$ & $0.16(0.075) *$ & $0.15(0.043) * * *$ & & & \\
\hline$X_{t+2}-X_{t}$ & $0.3(0.121) *$ & $0.21(0.081) * *$ & & & \\
\hline$X_{t+3}-X_{t}$ & $0.28(0.166)$ & $0.24(0.129)$ & & & \\
\hline
\end{tabular}


Table 23 Outcomes for firms chosen by FIIs but not DIIs: More extreme definitions of FII and DII ownership

\begin{tabular}{|c|c|c|c|c|c|}
\hline \multicolumn{3}{|c|}{ Log Gross Fixed Assets } & \multicolumn{3}{|c|}{ Log Total Assets } \\
\hline & OLS & Matching & & OLS & Matching \\
\hline$X_{t}-X_{t-2}$ & $0.06(0.04)$ & $0.1(0.054)$ & $X_{t}-X_{t-2}$ & $0.17(0.049) * * *$ & $0.11(0.04) * *$ \\
\hline$X_{t}-X_{t-1}$ & $0.04(0.025)$ & $0.05(0.029)$ & $X_{t}-X_{t-1}$ & $0.11(0.031) * * *$ & $0.06(0.021)$ ** \\
\hline$X_{t+1}-X_{t}$ & $0.05(0.032)$ & $0.11(0.035) * *$ & $X_{t+1}-X_{t}$ & $0.08(0.026) * *$ & $0.07(0.022)$ ** \\
\hline$X_{t+2}-X_{t}$ & $0.08(0.048)$ & $0.17(0.067) *$ & $X_{t+2}-X_{t}$ & $0.1(0.04) *$ & $0.11(0.043)$ ** \\
\hline$X_{t+3}-X_{t}$ & $0.13(0.06) *$ & $0.27(0.096) * *$ & $X_{t+3}-X_{t}$ & $0.1(0.052)$. & $0.13(0.063) *$ \\
\hline \multicolumn{3}{|c|}{ Log Employment } & \multicolumn{3}{|c|}{ Log Sales } \\
\hline & OLS & Matching & & OLS & Matching \\
\hline$X_{t}-X_{t-2}$ & $0.13(0.057) *$ & $0.06(0.058)$ & $X_{t}-X_{t-2}$ & $0.07(0.043)$ & $0.09(0.059)$ \\
\hline$X_{t}-X_{t-1}$ & $0.12(0.034) * * *$ & $0.04(0.033)$ & $X_{t}-X_{t-1}$ & $0.05(0.025)$. & $0.04(0.031)$ \\
\hline$X_{t+1}-X_{t}$ & $0.01(0.032)$ & $0.02(0.033)$ & $X_{t+1}-X_{t}$ & $0.06(0.028) *$ & $0(0.039)$ \\
\hline$X_{t+2}-X_{t}$ & $0.07(0.06)$ & $0.04(0.066)$ & $X_{t+2}-X_{t}$ & $0.14(0.052) * *$ & $0.01(0.068)$ \\
\hline$X_{t+3}-X_{t}$ & $0.1(0.085)$ & $0.03(0.092)$ & $X_{t+3}-X_{t}$ & $0.16(0.08) *$ & $0.02(0.097)$ \\
\hline \multicolumn{3}{|c|}{ Cobb Douglas Productivity Growth } & \multicolumn{3}{|c|}{ TFP (Log LP estimate) } \\
\hline & OLS & Matching & & OLS & Matching \\
\hline$X_{t}-X_{t-2}$ & $0.1(0.05)$ & $-0.04(0.034)$ & $X_{t}-X_{t-2}$ & $0.02(0.027)$ & $0.02(0.017)$ \\
\hline$X_{t}-X_{t-1}$ & $0.18(0.089) *$ & $-0.06(0.065)$ & $X_{t}-X_{t-1}$ & $0.01(0.014)$ & $0.01(0.009)$ \\
\hline$X_{t+1}-X_{t}$ & $-0.01(0.039)$ & $-0.11(0.05) *$ & $X_{t+1}-X_{t}$ & $-0.01(0.014)$ & $-0.01(0.009)$ \\
\hline$X_{t+2}-X_{t}$ & $0.06(0.068)$ & $-0.15(0.089)$. & $X_{t+2}-X_{t}$ & $0(0.022)$ & $0.01(0.017)$ \\
\hline$X_{t+3}-X_{t}$ & $0(0.101)$ & $-0.22(0.114)$. & $X_{t+3}-X_{t}$ & $0.01(0.022)$ & $0.01(0.024)$ \\
\hline \multicolumn{3}{|c|}{ Log Adjusted Closing Price } & & & \\
\hline & OLS & Matching & & & \\
\hline$\overline{X_{t}-X_{t-2}}$ & $0.19(0.121)$ & $-0.09(0.078)$ & & & \\
\hline$X_{t}-X_{t-1}$ & $0.23(0.078) * *$ & $-0.02(0.048)$ & & & \\
\hline$X_{t+1}-X_{t}$ & $-0.05(0.088)$ & $-0.1(0.057)$ & & & \\
\hline$X_{t+2}-X_{t}$ & $-0.14(0.122)$ & $-0.29(0.099) * *$ & & & \\
\hline$X_{t+3}-X_{t}$ & $-0.25(0.145)$ & $-0.38(0.144) * *$ & & & \\
\hline
\end{tabular}


Table 24 Outcomes for firms chosen by DIIs but not FIIs: More extreme definitions of FII and DII ownership

\begin{tabular}{|c|c|c|c|c|c|}
\hline \multicolumn{3}{|c|}{ Log Gross Fixed Assets } & \multicolumn{3}{|c|}{ Log Total Assets } \\
\hline & OLS & Matching & \multicolumn{2}{|r|}{ OLS } & Matching \\
\hline$X_{t}-X_{t-2}$ & $-0.14(0.029) * * *$ & $-0.07(0.033) *$ & $X_{t}-X_{t-2}$ & $.15(0.023) * * *$ & $-0.08(0.022) * * *$ \\
\hline$X_{t}-X_{t-1}$ & $-0.07(0.016) * * *$ & $-0.02(0.018)$ & $X_{t}-X_{t-1}$ & $.06(0.013) * * *$ & $-0.03(0.012) *$ \\
\hline$X_{t+1}-X_{t}$ & $-0.04(0.015) *$ & $-0.02(0.017)$ & $X_{t+1}-X_{t}$ & $.01(0.014)$ & $-0.01(0.012)$ \\
\hline$X_{t+2}-X_{t}$ & $-0.06(0.027) *$ & $-0.05(0.032)$ & $X_{t+2}-X_{t}$ & $.01(0.026)$ & $-0.04(0.023)$ \\
\hline$X_{t+3}-X_{t}$ & $-0.06(0.04)$ & $-0.08(0.045)$. & $X_{t+3}-X_{t}$ & $(0.037)$ & $-0.04(0.036)$ \\
\hline \multicolumn{3}{|c|}{ Log Employment } & \multicolumn{3}{|c|}{ Log Sales } \\
\hline & OLS & Matching & & OLS & Matching \\
\hline$X_{t}-X_{t-2}$ & $-0.1(0.031) * *$ & $-0.05(0.031)$ & $X_{t}-X_{t-2}$ & $-0.06(0.028) *$ & $-0.01(0.036)$ \\
\hline$X_{t}-X_{t-1}$ & $-0.04(0.018) *$ & $-0.02(0.019)$ & $X_{t}-X_{t-1}$ & $-0.03(0.019)$ & $-0.02(0.02)$ \\
\hline$X_{t+1}-X_{t}$ & $-0.05(0.022) *$ & $-0.01(0.021)$ & $X_{t+1}-X_{t}$ & $0(0.023)$ & $0(0.027)$ \\
\hline$X_{t+2}-X_{t}$ & $-0.06(0.033)$ & $-0.06(0.036)$ & $X_{t+2}-X_{t}$ & $0.06(0.039)$ & $0(0.042)$ \\
\hline$X_{t+3}-X_{t}$ & $-0.03(0.043)$ & $-0.1(0.048) *$ & $X_{t+3}-X_{t}$ & $0.08(0.048)$. & $0.01(0.052)$ \\
\hline \multicolumn{3}{|c|}{ Cobb Douglas Productivity Growth } & \multicolumn{3}{|c|}{ TFP (Log LP estimate) } \\
\hline & OLS & Matching & & OLS & Matching \\
\hline$X_{t}-X_{t-2}$ & $0.04(0.025)$. & $0(0.023)$ & $X_{t}-X_{t-2}$ & $0(0.01)$ & $0.01(0.009)$ \\
\hline$X_{t}-X_{t-1}$ & $0.08(0.045)$ & $0.05(0.039)$ & $X_{t}-X_{t-1}$ & $0(0.008)$ & $0(0.006)$ \\
\hline$X_{t+1}-X_{t}$ & $0.03(0.025)$ & $0.01(0.027)$ & $X_{t+1}-X_{t}$ & $0.01(0.007)$ & $-0.01(0.007)$ \\
\hline$X_{t+2}-X_{t}$ & $0.11(0.04) * *$ & $0.02(0.044)$ & $X_{t+2}-X_{t}$ & $0.02(0.009) * *$ & $0.01(0.01)$ \\
\hline$X_{t+3}-X_{t}$ & $0.14(0.055) *$ & $0.04(0.051)$ & $X_{t+3}-X_{t}$ & $0.03(0.01) *$ & $0.01(0.015)$ \\
\hline \multicolumn{3}{|c|}{ Log Adjusted Closing Price } & & & \\
\hline & OLS & Matching & & & \\
\hline$X_{t}-X_{t-2}$ & $0.1(0.07)$ & $0.01(0.054)$ & & & \\
\hline$X_{t}-X_{t-1}$ & $0.12(0.041) * *$ & $0.04(0.032)$ & & & \\
\hline$X_{t+1}-X_{t}$ & $0.25(0.05) * * *$ & $0.06(0.035)$. & & & \\
\hline$X_{t+2}-X_{t}$ & $0.36(0.077) * * *$ & $0.14(0.058) *$ & & & \\
\hline$X_{t+3}-X_{t}$ & $0.33(0.093) * * *$ & $0.24(0.082) * *$ & & & \\
\hline
\end{tabular}


$\overline{\text { Table } 25 \text { Outcomes for firms chosen by FIIs but not DIIs: Using turnover }}$ ratio for matching

\begin{tabular}{|c|c|c|c|c|c|}
\hline \multicolumn{3}{|c|}{ Log Gross Fixed Assets } & \multicolumn{3}{|c|}{ Log Total Assets } \\
\hline & OLS & Matching & & OLS & Matching \\
\hline$X_{t}-X_{t-2}$ & $0.08(0.033) *$ & $0.1(0.033) * *$ & $X_{t}-X_{t-2}$ & $0.15(0.035) * * *$ & $0.08(0.028) * *$ \\
\hline$X_{t}-X_{t-1}$ & $0.04(0.02) *$ & $0.06(0.017) * *$ & $X_{t}-X_{t-1}$ & $0.1(0.02) * * *$ & $0.04(0.015) * *$ \\
\hline$X_{t+1}-X_{t}$ & $0.06(0.021) * *$ & $0.05(0.018) * *$ & $X_{t+1}-X_{t}$ & $0.08(0.019) * * *$ & $0.05(0.015) * *$ \\
\hline$X_{t+2}-X_{t}$ & $0.08(0.033) *$ & $0.08(0.037) *$ & $X_{t+2}-X_{t}$ & $0.11(0.031) * * *$ & $0.07(0.03) *$ \\
\hline$X_{t+3}-X_{t}$ & $0.12(0.044) * *$ & $0.17(0.059) * *$ & $X_{t+3}-X_{t}$ & $0.13(0.043) * *$ & $0.13(0.048) * *$ \\
\hline \multicolumn{3}{|c|}{ Log Employment } & \multicolumn{3}{|c|}{ Log Sales } \\
\hline & OLS & Matching & & OLS & Matching \\
\hline$X_{t}-X_{t-2}$ & $0.17(0.044) * * *$ & $0.05(0.034)$ & $X_{t}-X_{t-2}$ & $0.03(0.033)$ & $0(0.037)$ \\
\hline$X_{t}-X_{t-1}$ & $0.1(0.025) * * *$ & $0.03(0.02)$ & $X_{t}-X_{t-1}$ & $0.04(0.018)$ & $0.01(0.021)$ \\
\hline$X_{t+1}-X_{t}$ & $0.02(0.024)$ & $0.02(0.023)$ & $X_{t+1}-X_{t}$ & $0.06(0.021) * *$ & $0.03(0.025)$ \\
\hline$X_{t+2}-X_{t}$ & $0.07(0.046)$ & $0.02(0.045)$ & $X_{t+2}-X_{t}$ & $0.11(0.041) * *$ & $0.04(0.047)$ \\
\hline$X_{t+3}-X_{t}$ & $0.07(0.067)$ & $0.06(0.065)$ & $X_{t+3}-X_{t}$ & $0.2(0.064)^{* *}$ & $0.12(0.072)$ \\
\hline \multicolumn{3}{|c|}{ Cobb Douglas Productivity Growth } & \multicolumn{3}{|c|}{ TFP (Log LP estimate) } \\
\hline & OLS & Matching & & OLS & Matching \\
\hline$X_{t}-X_{t-2}$ & $0.05(0.033)$ & $-0.06(0.023) *$ & $X_{t}-X_{t-2}$ & $0(0.016)$ & $-0.01(0.01)$ \\
\hline$X_{t}-X_{t-1}$ & $0.09(0.057)$ & $-0.1(0.042) *$ & $X_{t}-X_{t-1}$ & $0(0.008)$ & $-0.01(0.005)$ \\
\hline$X_{t+1}-X_{t}$ & $0.01(0.028)$ & $-0.02(0.029)$ & $X_{t+1}-X_{t}$ & $-0.01(0.009)$ & $0(0.007)$ \\
\hline$X_{t+2}-X_{t}$ & $0.05(0.049)$ & $-0.03(0.051)$ & $X_{t+2}-X_{t}$ & $0(0.012)$ & $0(0.013)$ \\
\hline$X_{t+3}-X_{t}$ & $0.07(0.069)$ & $-0.05(0.076)$ & $X_{t+3}-X_{t}$ & $0.01(0.013)$ & $0(0.018)$ \\
\hline \multicolumn{6}{|c|}{ Log Adjusted Closing Price } \\
\hline & OLS & Matching & & & \\
\hline$X_{t}-X_{t-2}$ & $0.21(0.092)^{*}$ & $-0.07(0.055)$ & & & \\
\hline$X_{t}-X_{t-1}$ & $0.19(0.059) * *$ & $-0.03(0.036)$ & & & \\
\hline$X_{t+1}-X_{t}$ & $0.01(0.07)$ & $-0.05(0.039)$ & & & \\
\hline$X_{t+2}-X_{t}$ & $-0.08(0.102)$ & $-0.08(0.068)$ & & & \\
\hline$X_{t+3}-X_{t}$ & $-0.09(0.124)$ & $-0.1(0.104)$ & & & \\
\hline
\end{tabular}


$\overline{\text { Table } 26 \text { Outcomes for firms chosen by DIIs but not FIIs: Using Turnover }}$ ratio for matching

\begin{tabular}{|c|c|c|c|c|c|c|}
\hline \multicolumn{3}{|c|}{ Log Gross Fixed Assets } & \multicolumn{4}{|c|}{ Log Total Assets } \\
\hline & OLS & Matching & \multicolumn{2}{|c|}{ OLS } & Matching & \\
\hline$X_{t}-X_{t-2}$ & $-0.1(0.02) * * *$ & $-0.04(0.019)$ & \multicolumn{2}{|c|}{$-0.09(0.018) * * *$} & $-0.06(0.015) *$ & k** \\
\hline$X_{t}-X_{t-1}$ & $-0.05(0.011) * * *$ & $-0.02(0.011)$ & $X_{t}-X_{t-1}$ & $-0.04(0.01) * * *$ & $-0.02(0.008) *$ & \\
\hline$X_{t+1}-X_{t}$ & $-0.02(0.01) *$ & $0(0.012)$ & $X_{t+1}-X_{t}$ & $-0.01(0.01)$ & $-0.01(0.009)$ & \\
\hline$X_{t+2}-X_{t}$ & $-0.05(0.02) *$ & $-0.01(0.022)$ & $X_{t+2}-X_{t}$ & $-0.02(0.018)$ & $-0.01(0.017)$ & \\
\hline$X_{t+3}-X_{t}$ & $-0.05(0.03)$ & $-0.02(0.032)$ & $X_{t+3}-X_{t}$ & $-0.01(0.026)$ & $-0.02(0.025)$ & \\
\hline \multicolumn{3}{|c|}{ Log Employment } & \multicolumn{4}{|c|}{ Log Sales } \\
\hline & OLS & Matching & & OLS & Matching & \\
\hline$X_{t}-X_{t-2}$ & $-0.06(0.024) *$ & $-0.01(0.021)$ & $X_{t}-X_{t-2}$ & $-0.05(0.021)^{*}$ & $0(0.028)$ & \\
\hline$X_{t}-X_{t-1}$ & $-0.03(0.013) *$ & $0.02(0.013)$ & $X_{t}-X_{t-1}$ & $-0.02(0.012)$ & $0.01(0.016)$ & \\
\hline$X_{t+1}-X_{t}$ & $-0.03(0.015)$ & $-0.01(0.013)$ & $X_{t+1}-X_{t}$ & $0.01(0.015)$ & $0.01(0.017)$ & \\
\hline$X_{t+2}-X_{t}$ & $-0.03(0.026)$ & $-0.02(0.024)$ & $X_{t+2}-X_{t}$ & $0.03(0.027)$ & $0.01(0.031)$ & \\
\hline$X_{t+3}-X_{t}$ & $-0.01(0.036)$ & $-0.04(0.034)$ & $X_{t+3}-X_{t}$ & $0.05(0.039)$ & $0.04(0.042)$ & \\
\hline \multicolumn{3}{|c|}{ Cobb Douglas Productivity Growth } & \multicolumn{4}{|c|}{ TFP (Log LP estimate) } \\
\hline & OLS & Matching & & OLS & Matching & \\
\hline$X_{t}-X_{t-2}$ & $0.02(0.019)$ & $0.02(0.016)$ & $X_{t}-X_{t-2}$ & $0(0.007)$ & $0(0.006)$ & \\
\hline$X_{t}-X_{t-1}$ & $0.04(0.031)$ & $0.03(0.028)$ & $X_{t}-X_{t-1}$ & $0(0.005)$ & $0(0.003)$ & \\
\hline$X_{t+1}-X_{t}$ & $0.03(0.017)$ & $0(0.018)$ & $X_{t+1}-X_{t}$ & $0.01(0.004)$ & $0(0.004)$ & \\
\hline$X_{t+2}-X_{t}$ & $0.09(0.03) * *$ & $0.02(0.029)$ & $X_{t+2}-X_{t}$ & $0.02(0.006) *$ & $0.01(0.006) *$ & \\
\hline$X_{t+3}-X_{t}$ & $0.11(0.041)^{* *}$ & $0.07(0.041)$. & $X_{t+3}-X_{t}$ & $0.01(0.008)$ & $0.02(0.009) *$ & \\
\hline \multicolumn{3}{|c|}{ Log Adjusted Closing Price } & & & & \\
\hline & OLS & Matching & & & & \\
\hline$X_{t}-X_{t-2}$ & $0.05(0.052)$ & $0.01(0.036)$ & & & & \\
\hline$X_{t}-X_{t-1}$ & $0.04(0.03)$ & $0.03(0.021)$ & & & & \\
\hline$X_{t+1}-X_{t}$ & $0.16(0.034) * * *$ & $0.06(0.023) * *$ & & & & \\
\hline$X_{t+2}-X_{t}$ & $0.21(0.053) * * *$ & $0.1(0.038) * *$ & & & & \\
\hline$X_{t+3}-X_{t}$ & $0.22(0.066) * * *$ & $0.18(0.056) * *$ & & & & \\
\hline
\end{tabular}




\section{References}

Albuquerque, R., G. H Bauer, and M. Schneider (2009): "Global private information in international equity markets," Journal of Financial Economics, 94(1), 18-46.

Choe, H., B.-C. Kho, And R. M. Stulz (2005): "Do Domestic Investors Have an Edge? The Trading Experience of Foreign Investors in Korea," Review of financial studies, 18(3), 795-829.

Dahlquist, M., and G. Robertsson (2001): "Direct foreign ownership, institutional investors, and firm characteristics," Journal of Financial Economics, 59(3), 413-440.

Desai, H., K. Ramesh, S. Thiagarajan, and B. Balachandran (2002): "An investigation of the informational role of short interest in the Nasdaq market," The Journal of Finance, 57(5), 2263-2287.

Dvořák, T. (2005): "Do domestic investors have an information advantage? Evidence from Indonesia," The Journal of Finance, 60(2), 817-839.

Fama, E., And K. French (1993): "Common risk factors in the returns on stocks and bonds," Journal of Financial Economics, 33(1), 3-56.

Froot, K., And T. Ramadorai (2008): "Institutional portfolio flows and international investments," Review of Financial Studies, 21(2), 937-971.

Jegadeesh, N., And S. Titman (1993): "Returns to buying winners and selling losers: Implications for stock market efficiency," The Journal of Finance, 48(1), 65-91.

Levinsohn, J., And A. Petrin (2003): "Estimating Production Functions Using Inputs to Control for Unobservables," Review of Economic Studies, 70, 317-341.

Merton, R. (1987): "A Simple Model of Capital Market Equilibrium with Incomplete Information," The Journal of Finance, 42(3), 483-510.

Petkova, N. (2012): "The real effects of foreign investment: Productivity and growth," Discussion paper, Department of Finance, University of Oregon.

Stuart, E. A. (2010): "Matching methods for causal inference: A Review and a Look Forward," Statistical Science, 25(1), 1-21. 